\title{
${ }^{\partial}$ Bayesian Assimilation of Multiscale Precipitation Data and Sparse Ground Gauge Observations in Mountainous Areas 0
}

\author{
YUHAN WANG \\ State Key Laboratory of Hydroscience and Engineering, Department of Hydraulic Engineering, Tsinghua \\ University, Beijing, China, and Earth and Environmental Sciences Area, Lawrence Berkeley National \\ Laboratory, Berkeley, California \\ JINSONG CHEN \\ Earth and Environmental Sciences Area, Lawrence Berkeley National Laboratory, Berkeley, California
}

DAWEN YANG

State Key Laboratory of Hydroscience and Engineering, Department of Hydraulic Engineering, Tsinghua University, Beijing, China

(Manuscript received 16 October 2018, in final form 20 March 2019)

\begin{abstract}
Estimating the spatial distribution of precipitation is important for understanding ecohydrological processes at catchment scales. However, this estimation is difficult in mountainous areas because ground-based observation stations are often sparsely located and do not represent the spatial variability of precipitation. In this study, we develop a Bayesian assimilation method based on data collected on the Tibetan Plateau from 1980 to 2014 to estimate monthly and daily precipitation. To accomplish this, point-scale ground meteorological observations are combined with large-scale precipitation data such as satellite observations or reanalysis data. First, we remove the terrain effects from ground observations by fitting the precipitation data as functions of elevation, and then we spatially interpolate the residuals to 5-km-resolution grids to obtain monthly and daily precipitation. Additionally, we use Tropical Rainfall Measuring Mission (TRMM) satellite observations and ERA-Interim reanalysis data. Cross-validation methods are used to evaluate our method; the results show that our method not only captures the change in precipitation with terrain but also significantly reduces the associated uncertainty. The improvements are more evident in the main river source areas on the edge of the Tibetan Plateau, where elevation changes dramatically, and in high-altitude areas, where the ground gauges are sparse compared with those in low-altitude areas. Our assimilation method is applicable to other regions and is particularly useful for mountainous watersheds where ground meteorological stations are sparse and precipitation is considerably influenced by terrain.
\end{abstract}

\section{Introduction}

Precipitation is one of the fundamental drivers of ecohydrological processes in a watershed (Kaptué et al. 2015; Li et al. 2013) because the spatial distribution of precipitation influences the spatial distribution of runoff,

¿ Denotes content that is immediately available upon publication as open access.

Supplemental information related to this paper is available at the Journals Online website: https://doi.org/10.1175/JHM-D-18-0218.s1.

Corresponding author: Dawen Yang, yangdw@tsinghua.edu.cn evaporation, and soil moisture; thus, the ecological processes are also influenced (Nykanen et al. 2001; Taylor et al. 1997). Estimating the spatial distribution of precipitation in mountainous regions is particularly important for understanding the spatial characteristics of ecohydrology in these regions (Immerzeel et al. 2009; Wang et al. 2017). However, estimating precipitation in mountainous regions is very challenging because complex topographic effects restrict access and cause high spatial variability (Guan et al. 2005).

Mountain precipitation is commonly affected by topography and thus has high spatial variability (Basist et al. 1994; Guan et al. 2005; Lloyd 2005). Precipitation on the top of a mountain may be significantly different 
from that at the foot of the mountain (Daly et al. 2008; Sanberg and Oerlemans 1983). Consequently, estimating precipitation in mountainous areas requires many more gauge stations than in plains areas. However, due to the complex terrain and sparse population, ground gauges are usually built at low altitudes and are scarce and unevenly located in mountainous areas (Wang et al. 2017). Consequently, it is difficult to represent the spatial variability of precipitation in mountainous areas with gauge observations (Daly et al. 2008).

Other precipitation data, such as remote sensing data (e.g., satellite data and radar observations) and modelbased data [e.g., simulation and reanalysis results of general circulation models (GCMs)], are also defective when applied to mountainous regions (Fowler et al. 2007; Hofstra et al. 2008; Wang et al. 2017). Satellite data, such as Tropical Rainfall Measuring Mission (TRMM; Huffman et al. 2007a) and CPC morphing technique (CMORPH; Joyce et al. 2004), often contain greater uncertainties in mountainous areas than in plains areas (Xu et al. 2017). Moreover, satellite precipitation often has a low spatial resolution, which makes the high spatial variability of precipitation in mountainous regions difficult to accurately depict (Hofstra et al. 2008). Similar limitations exist with model-based precipitation (Wood et al. 2004; Fowler et al. 2007). Radar data also have considerable limitations when used in mountainous areas, especially on the Tibetan Plateau. The complex terrain often causes beam blocking and interference with radar observations. Moreover, in alpine areas, ice phase hydrometeors may have weaker reflectivity, which also leads to the distortion of the observations. As a result, radar observations of precipitation in mountainous areas are often subject to a large degree of uncertainty (Young et al. 1999; Li et al. 2014).

Many previous studies have attempted to estimate the spatial distribution of precipitation in mountainous areas (Kirshbaum and Durran 2005a,b; Kingsmill et al. 2006; Smith and Evans 2007; Giovannettone and Barros 2009; Lundquist et al. 2010; Mass et al. 2015; Newman et al. 2015). These studies include gauge-based estimates, remote sensing-based estimates, model-based estimates, and assimilation-based estimates from ground gauge and satellite data (Gottschalck et al. 2005). According to ground gauge observations, Daly et al. (1994) developed a method that utilizes a local regression technique to account for the effect of terrain. This strategy was adopted in several later studies (Shen and Xiong 2016; Xie et al. 2007). However, because gauges are generally sparsely located in mountainous areas, the estimated precipitation based on gauge data alone is highly uncertain, even if the precipitation-elevation relationship is considered. Wang et al. (2017) proposed a new spatial interpolation method that merges the precipitation-elevation information provided by a highly accurate regional climate model (RCM). However, due to the lack of RCM data in many mountainous regions, the applicability of this method remains limited.

Certain remote sensing-based studies have established statistical models combining satellite precipitation and other environmental factors with high spatial accuracy, such as vegetation and topography, in order to downscale the precipitation data (Guan et al. 2009; Immerzeel et al. 2009; Jia et al. 2011). Model-based estimation methods often utilize data assimilation strategies to dynamically downscale low-resolution climate modeling results (e.g., GCM's output and reanalysis data) to highresolution data, such as studies by Xiong and Yan (2013) and Pan et al. (2015) on the northeastern Tibetan Plateau. The main advantage of model-based estimation is that models can output different climate elements in addition to precipitation with high spatial resolution. The common weakness of both remote sensing-based and model-based estimations is that despite improved spatial resolution through downscaling, these estimates are often subject to a large degree of uncertainty due to the lack of gauge observations for calibration (Fowler et al. 2007; Tobin and Bennett 2010).

Assimilation-based methods attempt to combine different sources of information to obtain optimal precipitation estimation (Bianchi et al. 2013; Prasanna et al. 2014; Sun et al. 2018). Most of these studies rectify satellite data by comparing the differences between satellite data and gauge observations (Gottschalck et al. 2005; Prasanna et al. 2014; Tobin and Bennett 2010). The main advantage of these methods is that they utilize both point-scale information provided by gauge observations and the spatial distribution information provided by satellite data. However, these methods still have limitations since they cannot identify relatively effective information from different precipitation measurement sources (Li 2015). Moreover, the temporal and spatial patterns of the uncertainty in the merged precipitation, which are also important, cannot be obtained in those methods (Alemohammad et al. 2015; Li 2015).

Bayesian methods are commonly used for uncertainty analysis of hydrological models and their inputs (Li et al. 2012) and provide a general framework for multiscale data assimilation (Kavetski et al. 2006). Bayesian models have been applied to many studies of multisource precipitation data assimilation (Barillec and Cornford 2009; Li 2015). For example, Li (2015) developed a Bayesian method to merge gauge observations and satellite precipitation, and this method can estimate both the relatively effective information of gauge and satellite data and the spatial distribution of merged precipitation. This method has been shown to 
perform well in plains areas. However, this method cannot be directly used for mountainous areas because the method does not consider the influence of terrain on precipitation, which is arguably a major factor that leads to great uncertainty in the merged precipitation.

In this study, we develop a multiscale Bayesian model for estimating precipitation distribution in mountainous regions by integrating gauge-based measurements with spatially distributed satellite data. We apply the method to the Tibetan Plateau to generate highresolution monthly and daily precipitation from 1980 to 2014. The methodology is given in detail in section 2, and the application of the method to the Tibetan Plateau region is presented in section 3. In section 4, we first show the validation and evaluation of the method, and then the limitations of the proposed method are discussed. Finally, the conclusions are presented in section 5 .

\section{Methodology}

\section{a. Bayesian model for assimilating data from mountainous areas}

We developed a Bayesian model to estimate the spatial distribution of mountainous area precipitation using ground gauge observations and reference precipitation products, such as satellite observations and reanalysis data. First, we divided the studied basin into many finescale (e.g., 5-km spatial resolution) grid cells. Let $x\left(\mathbf{u}_{i}\right)$ represent precipitation at the $i$ th grid, $i \in N=$ $\{1,2, \ldots, n\}$, where $n$ is the total number of grids and vector $\mathbf{u}_{i}$ represents the coordinates of the $i$ th grid central location. Let $y_{1}\left(\mathbf{u}_{i}\right), y_{2}\left(\mathbf{u}_{i}\right), \ldots, y_{m}\left(\mathbf{u}_{i}\right)$ denote the corresponding reference precipitation values, which are downscaled from $m$ different types of satellite products or reanalysis data. Let $N_{o}$ represent all the indices where we have ground-based observations; thus, we only need to estimate $x\left(\mathbf{u}_{i}\right)$ for $i \in N \backslash N_{o}$.

Since the total number of grid cells in a catchment at fine scales is very large (e.g., thousands of millions), we adopt a two-step approach for pixelwise integration of multiscale data. This method is similar in principle to the one developed by Chen et al. (2001) for integrating borehole measurements of hydraulic permeability and cross-well geophysical tomographic data. First, we use geostatistical methods (Kitanidis 1997) to spatially interpolate ground-based measurements $\left\{x\left(\mathbf{u}_{i}\right), i \in N_{o}\right\}$ to each grid cell for which we do not have direct measurements, and we use the estimates to define a prior probability distribution. Then, we update the prior distribution by using its collocated reference precipitation values. The pixelwise Bayesian model is as follows:

$$
\begin{array}{r}
f\left[x\left(\mathbf{u}_{i}\right) \mid y_{1}\left(\mathbf{u}_{i}\right), \ldots, y_{m}\left(\mathbf{u}_{i}\right)\right] \propto f\left[x\left(\mathbf{u}_{i}\right)\right] \\
\times \prod_{k=1}^{m} f\left[y_{k}\left(\mathbf{u}_{i}\right) \mid x\left(\mathbf{u}_{i}\right)\right],
\end{array}
$$

where $f(\cdot)$ is the prior distribution of precipitation and $f(\cdot \cdot)$ is the likelihood function of the reference precipitation values or conditional probability distributions. We provide more details later in the manuscript.

\section{b. Likelihood functions for reference precipitation data}

First, we develop likelihood models using gauge observations and their collocated reference values. Several previous studies have shown that both satellite-based and climate model-based precipitation correspond with gauge-based observations, and the relationships can be described by linear or nonlinear statistical models (Cuo and Zhang 2017; Tong et al. 2014). Among the many methods, additive and multiplicative error models are widely adopted (Li 2015; Tian et al. 2013). For ease of description, we describe the likelihood functions for only one type of reference data, although our method is applicable to multiple types of reference data. We assume that the measurement errors at gauges are negligible compared to the uncertainty in the satellite observations or climate model simulation results. Consequently, we can treat the gauge measurements as true precipitation.

For the additive error model, we assume that reference precipitation values linearly depend on their collocated gauge measurements with Gaussian residuals. Specifically,

$$
y_{k}\left(\mathbf{u}_{i}\right)=a_{k}\left(\mathbf{u}_{i}\right)+b_{k}\left(\mathbf{u}_{i}\right) x\left(\mathbf{u}_{i}\right)+\varepsilon_{k}\left(\mathbf{u}_{i}\right), i \in N_{0},
$$

where $a_{k}\left(\mathbf{u}_{i}\right)$ and $b_{k}\left(\mathbf{u}_{i}\right)$ are the intercept and slope, respectively, of the linear model for the $k$ th type of reference data. We assume that $\varepsilon_{k}\left(\mathbf{u}_{i}\right)$ has a Gaussian distribution with a zero mean and standard deviation of $\sigma_{k}\left(\mathbf{u}_{i}\right)$. We can obtain all of these parameters at each gauge station by performing a linear regression of $y_{k}\left(\mathbf{u}_{i}\right)$ versus $x\left(\mathbf{u}_{i}\right)$ based on data from different times. These parameters are spatially interpolated to the grids for which no gauge observations are available using the angular distance weighting (ADW) method, which is a common spatial interpolation approach for areas where ground gauge stations are unevenly located (Shepard 1968; Hofstra and New 2009; New et al. 2000; Wang et al. 2017; Willmott et al. 1985). As a result, we have the following likelihood model at each grid: 


$$
\begin{aligned}
f\left[y_{k}\left(\mathbf{u}_{i}\right) \mid x\left(\mathbf{u}_{i}\right)\right] \propto & \frac{1}{\sigma_{k}\left(\mathbf{u}_{i}\right)} \exp \left(-\frac{1}{2 \sigma_{k}^{2}\left(\mathbf{u}_{i}\right)}\left\{y_{k}\left(\mathbf{u}_{i}\right)\right.\right. \\
& \left.\left.-\left[a_{k}\left(\mathbf{u}_{i}\right)+b_{k}\left(\mathbf{u}_{i}\right) x\left(\mathbf{u}_{i}\right)\right]\right\}^{2}\right) .
\end{aligned}
$$

Similarly, we can define a likelihood function for the multiplicative error models by performing a logarithmic operation on both reference and gauge measurements before conducting a regression analysis.

\section{c. Gauge precipitation interpolation and prior model}

We use the ADW method to spatially interpolate gauge measurements to locations where ground-based measurements are not available, as in many previous studies (New et al. 2000; Wang et al. 2017; Willmott et al. 1985). Similar to Chen et al. (2001) and $\mathrm{Li}$ (2015), we define our prior model as the Gaussian distribution.

First, we must derive semivariogram functions from gauge observations to estimate the uncertainty in the spatial interpolation of gauge observations (Haberlandt 2007; Ly et al. 2011; Rogelis and Werner 2013). Under the assumption of second-order stationarity (Cressie 1993), we typically calculate empirical variograms as follows:

$$
\hat{\gamma}(\mathbf{h})=\frac{1}{2 n(\mathbf{h})} \sum_{i=1}^{n(\mathbf{h})}\left[x\left(\mathbf{u}_{i}+\mathbf{h}\right)-x\left(\mathbf{u}_{i}\right)\right]^{2},
$$

where $n(\mathbf{h})$ denotes the total number of gauge pairs with distance $\mathbf{h}$ and $x\left(\mathbf{u}_{i}+\mathbf{h}\right)$ and $x\left(\mathbf{u}_{i}\right)$ denote the observations at two gauges separated by distance $\mathbf{h}$. We can fit the empirical variogram with different types of theoretical models, such as the exponential model, the Gaussian model, and the spherical model, depending on the data (Cressie 1993).

However, in mountainous regions, due to the complex terrain, the typical spatial stationarity assumption cannot be satisfied, and elevation often has significant effects on precipitation. To account for both elevation and distance between gauge stations, we modify Eq. (4) as follows:

$$
\begin{aligned}
\hat{\gamma}(\mathbf{h}) & =\frac{1}{2 n(\mathbf{h})} \sum_{i=1}^{n(\mathbf{h})}\left\{\left[x\left(\mathbf{u}_{i}+\mathbf{h}\right)-S\left(\mathbf{u}_{i}, \mathbf{u}_{i}+\mathbf{h}\right) \operatorname{ele}\left(\mathbf{u}_{i}+\mathbf{h}\right)\right]-\left[x\left(\mathbf{u}_{i}\right)-S\left(\mathbf{u}_{i}, \mathbf{u}_{i}+\mathbf{h}\right) \operatorname{ele}\left(\mathbf{u}_{i}\right)\right]\right\}^{2} \\
& =\frac{1}{2 n(\mathbf{h})} \sum_{i=1}^{n(\mathbf{h})}\left\{x\left(\mathbf{u}_{i}+\mathbf{h}\right)-x\left(\mathbf{u}_{i}\right)-S\left(\mathbf{u}_{i}, \mathbf{u}_{i}+\mathbf{h}\right)\left[\operatorname{ele}\left(\mathbf{u}_{i}+\mathbf{h}\right)-\operatorname{ele}\left(\mathbf{u}_{i}\right)\right]\right\}^{2}
\end{aligned}
$$

where ele $\left(\mathbf{u}_{i}+\mathbf{h}\right)$ and ele $\left(\mathbf{u}_{i}\right)$ denote the elevations at the two gauges and $S\left(\mathbf{u}_{i}, \mathbf{u}_{i}+\mathbf{h}\right)$ denotes the average precipitation-elevation slope along the path from $\mathbf{u}_{i}$ to $\left(\mathbf{u}_{i}+\mathbf{h}\right)$, which is estimated as follows (Wang et al. 2017):

$$
S\left(\mathbf{u}_{i}, \mathbf{u}_{i}+\mathbf{h}\right)=\left(\sum_{j=1}^{\mathrm{Nop}-1}\left\{\operatorname{slope}_{j} \times\left[\operatorname{ele}\left(\mathbf{u}_{j+1}\right)-\operatorname{ele}\left(\mathbf{u}_{j}\right)\right]\right\}\right) /\left[\operatorname{ele}\left(\mathbf{u}_{i}+\mathbf{h}\right)-\operatorname{ele}\left(\mathbf{u}_{i}\right)\right]
$$

where Nop is the total number of pixels along the direction from the gauge station at $\mathbf{u}_{i}$ to the gauge station at $\left(\mathbf{u}_{i}+\mathbf{h}\right)$ and $j$ is the serial number of the Nop pixels. The pixel with $j=1$ denotes the pixel where the $\mathbf{u}_{i}$ station is located, while the pixel with $j=$ Nop denotes the pixel where the $\left(\mathbf{u}_{i}+\mathbf{h}\right)$ station is located. The slope ${ }_{j}$ denotes the precipitation-elevation slope at the $j$ th pixel, which is estimated through a linear regression model based on the observations of the eight nearest gauge stations. Figure 1 is a schematic figure to clarify the calculation of $S\left(\mathbf{u}_{i}, \mathbf{u}_{i}+\mathbf{h}\right)$ in Eq. (6).

After obtaining empirical semivariogram functions, we can estimate the spatially distributed uncertainty in the precipitation. In this study, we use the ADW interpolation method rather than commonly used kriging methods because the ADW method is more suitable for areas where ground gauges are not evenly distributed (Shepard 1968; Hofstra and New 2009; New et al. 2000; Wang et al. 2017; Willmott et al. 1985). In the ADW method, the interpolated precipitation at location $\mathbf{u}_{i}$ is calculated as follows:

$$
\begin{aligned}
x_{\mathrm{ADW}}\left(\mathbf{u}_{i}\right)= & \sum_{g=1}^{\mathrm{Nog}}\left(w_{g}\left(\mathbf{u}_{i}\right) \times\left\{x\left(\mathbf{u}_{g}\right)+S\left[\mathbf{u}_{i}, \mathbf{h}\left(\mathbf{u}_{g}, \mathbf{u}_{i}\right)\right]\right.\right. \\
& \left.\left.\times\left[\operatorname{ele}\left(\mathbf{u}_{i}\right)-\operatorname{ele}\left(\mathbf{u}_{g}\right)\right]\right\}\right) / \sum_{g=1}^{\operatorname{Nog}} w_{g}\left(\mathbf{u}_{i}\right),
\end{aligned}
$$




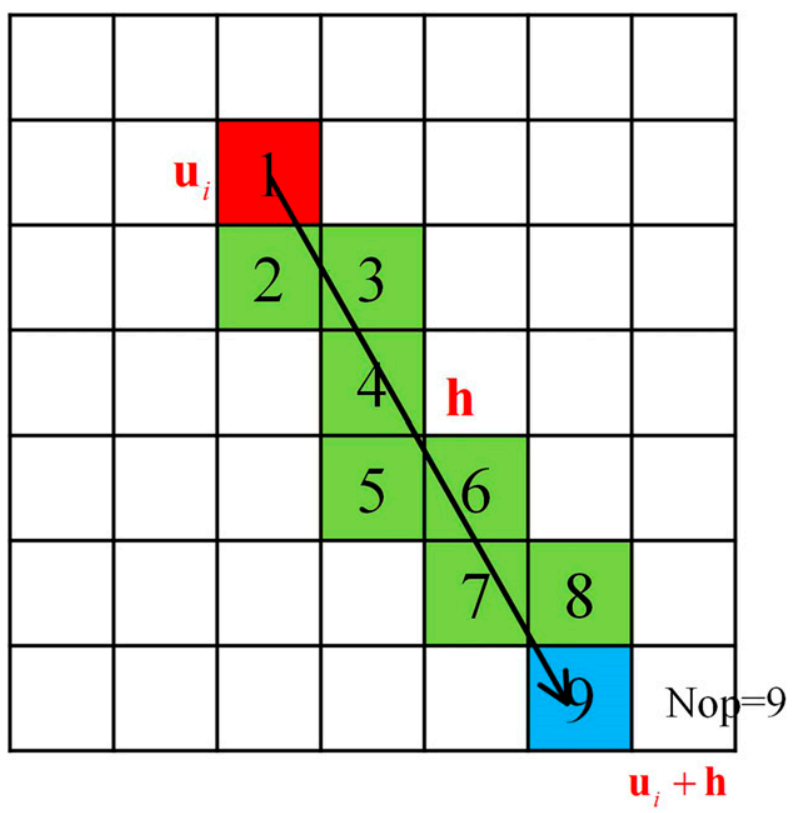

FIG. 1. A schematic figure for the calculation of the average precipitation-elevation slope along the path from $\mathbf{u}_{i}$ to $\left(\mathbf{u}_{i}+\mathbf{h}\right)$ in Eq. (6).

where Nog is the number of stations used to interpolate the target pixel and $w_{g}\left(\mathbf{u}_{i}\right)$ is the angular distance weight for gauge $g$. The calculation method of the angular distance weight is detailed in the online supplemental material.

The interpolation variance is calculated as follows (Delhomme 1978):

$$
\begin{aligned}
\sigma_{\text {ADW }}^{2}\left(\mathbf{u}_{i}\right)= & 2 \sum_{g=1}^{\text {Nog }} w_{g}\left(\mathbf{u}_{i}\right) \hat{\gamma}\left[\mathbf{h}\left(\mathbf{u}_{g}, \mathbf{u}_{i}\right)\right] \\
& -\sum_{g=1}^{\text {Nog Nog }} \sum_{l=1} w_{g}\left(\mathbf{u}_{i}\right) w_{l}\left(\mathbf{u}_{i}\right) \hat{\gamma}\left[\mathbf{h}\left(\mathbf{u}_{g}, \mathbf{u}_{l}\right)\right]-\hat{\gamma}(0) .
\end{aligned}
$$

Similar to Chen et al. (2001), we assume that precipitation at the finescale follows the Gaussian distribution with the interpolated result $\left[x_{\mathrm{ADW}}\left(\mathbf{u}_{i}\right)\right]$ as the mean and $\sigma_{\mathrm{ADW}}^{2}\left(\mathbf{u}_{i}\right)$ as the variance. Thus, we obtain the prior distribution at each pixel as follows:

$$
\begin{aligned}
f\left[x\left(\mathbf{u}_{i}\right)\right] \propto & \frac{1}{\sigma_{\mathrm{ADW}}\left(\mathbf{u}_{i}\right)} \exp \left\{-\frac{1}{2 \sigma_{\mathrm{ADW}}^{2}\left(\mathbf{u}_{i}\right)}\left[x\left(\mathbf{u}_{i}\right)\right.\right. \\
& \left.\left.-x_{\mathrm{ADW}}\left(\mathbf{u}_{i}\right)\right]^{2}\right\} .
\end{aligned}
$$

Note that the precipitation-elevation slopes are estimated only at the monthly scale. At the daily scale, since different precipitation events may vary greatly, we modify the method given in Eqs. (7) and (8) (Wang et al. 2017). First, we estimate the long-term mean spatial distribution of monthly precipitation and consider it to be precipitation climatology. We assume that the daily precipitation climatology is equal to the monthly climatology divided by the number of days in the month. We calculate the ratio of daily precipitation observations to the daily climatology at each gauge as follows (Wang et al. 2017):

$$
\operatorname{ratio}\left(\mathbf{u}_{i}\right)=\frac{x\left(\mathbf{u}_{i}\right)}{x_{\text {cli }}\left(\mathbf{u}_{i}\right)}
$$

where $x_{\mathrm{cli}}\left(\mathbf{u}_{i}\right)$ denotes the daily precipitation climatology at gauge $\mathbf{u}_{i}$. Then, we spatially interpolate the ratios instead of daily precipitation using the ADW method. Furthermore, the semivariogram [Eq. (5)] is also modified as follows:

$$
\hat{\gamma}(\mathbf{h})=\frac{1}{2 n(\mathbf{h})} \sum_{i=1}^{n(\mathbf{h})}\left[\operatorname{ratio}\left(\mathbf{u}_{i}+\mathbf{h}\right)-\operatorname{ratio}\left(\mathbf{u}_{i}\right)\right]^{2} .
$$

In this case, we modify the calculations of the mean [Eq. (7)] and variance [Eq. (8)] accordingly as follows:

$$
\begin{aligned}
E\left[x\left(\mathbf{u}_{i}\right)\right]= & x_{\mathrm{cli}}\left(\mathbf{u}_{i}\right) \times \operatorname{ratio}_{\mathrm{ADW}}\left(\mathbf{u}_{i}\right) \\
= & x_{\mathrm{cli}}\left(\mathbf{u}_{i}\right) \times\left\{\sum _ { g = 1 } ^ { \mathrm { Nog } } \left[w_{g}\left(\mathbf{u}_{i}\right)\right.\right. \\
& \left.\left.\times \operatorname{ratio}\left(\mathbf{u}_{g}\right)\right]\right\} / \sum_{g=1}^{\mathrm{Nog}} w_{g}\left(\mathbf{u}_{i}\right), \text { and } \\
\sigma_{\mathrm{ADW}}^{2}\left(\mathbf{u}_{i}\right)= & x_{\mathrm{cli}}^{2}\left(\mathbf{u}_{i}\right) \times\left\{2 \sum_{g=1}^{\mathrm{Nog}} w_{g}\left(\mathbf{u}_{i}\right) \hat{\gamma}\left[\mathbf{h}\left(\mathbf{u}_{g}, \mathbf{u}_{i}\right)\right]\right. \\
& \left.-\sum_{g=1}^{\operatorname{Nog}} \sum_{l=1}^{\mathrm{Nog}} w_{g}\left(\mathbf{u}_{i}\right) w_{l}\left(\mathbf{u}_{i}\right) \hat{\gamma}\left[\mathbf{h}\left(\mathbf{u}_{g}, \mathbf{u}_{l}\right)\right]-\hat{\gamma}(0)\right\} .
\end{aligned}
$$

The advantage of the modification in the daily precipitation estimation is that the variation in daily precipitation with elevation is considered by the monthly climatology, and the ratio is no longer affected by elevation.

\section{d. Posterior distribution and Markov chain Monte Carlo sampling}

Based on Eqs. (3) and (9), we can obtain a pixelwise posterior distribution as follows: 


$$
\begin{aligned}
f\left[x\left(\mathbf{u}_{i}\right) \mid y_{1}\left(\mathbf{u}_{i}\right), \ldots, y_{m}\left(\mathbf{u}_{i}\right)\right] & \propto \frac{1}{\sigma_{\mathrm{ADW}}\left(\mathbf{u}_{i}\right)} \exp \left\{-\frac{1}{2 \sigma_{\mathrm{ADW}}^{2}\left(\mathbf{u}_{i}\right)}\left[x\left(\mathbf{u}_{i}\right)-x_{\mathrm{ADW}}\left(\mathbf{u}_{i}\right)\right]^{2}\right\} \\
& \times \prod_{k=1}^{m} \frac{1}{\sigma_{k}\left(\mathbf{u}_{i}\right)} \exp \left(-\frac{1}{2 \sigma_{k}^{2}\left(\mathbf{u}_{i}\right)}\left\{y_{k}\left(\mathbf{u}_{i}\right)-\left[a_{k}\left(\mathbf{u}_{i}\right)+b_{k}\left(\mathbf{u}_{i}\right) x\left(\mathbf{u}_{i}\right)\right]\right\}^{2}\right) .
\end{aligned}
$$

From Eq. (14), we can derive the posterior distribution of $x\left(\mathbf{u}_{i}\right)$, which is also a normal distribution:

$$
\begin{gathered}
f\left[x\left(\mathbf{u}_{i}\right) \mid y_{1}\left(\mathbf{u}_{i}\right), \ldots, y_{m}\left(\mathbf{u}_{i}\right)\right] \propto \frac{1}{\sigma_{\mathrm{ADW}}\left(\mathbf{u}_{i}\right)} \exp \{- \\
\left.-0.5 \tau_{\mathrm{ADW}}\left(\mathbf{u}_{i}\right)\left[x\left(\mathbf{u}_{i}\right)-x_{\mathrm{ADW}}\left(\mathbf{u}_{i}\right)\right]^{2}\right\} \times \prod_{k=1}^{m} \frac{1}{\sigma_{k}\left(\mathbf{u}_{i}\right)} \exp \left(-0.5 \tau_{k}\left(\mathbf{u}_{i}\right)\left\{y_{k}\left(\mathbf{u}_{i}\right)\right.\right. \\
\left.\left.-\left[a_{k}\left(\mathbf{u}_{i}\right)+b_{k}\left(\mathbf{u}_{i}\right) x\left(\mathbf{u}_{i}\right)\right]\right\}^{2}\right) \propto N\left[x_{\mathrm{POST}}\left(\mathbf{u}_{i}\right), \tau_{\mathrm{POST}}\left(\mathbf{u}_{i}\right)\right],
\end{gathered}
$$

where $\tau_{k}\left(\mathbf{u}_{i}\right)$ and $\tau_{\mathrm{ADW}}\left(\mathbf{u}_{i}\right)$ are the inverse variance of the prior distribution and likelihood functions, respectively, and $x_{\mathrm{POST}}\left(\mathbf{u}_{i}\right)$ and $\tau_{\mathrm{POST}}\left(\mathbf{u}_{i}\right)$ are the mean and inverse variance of the posterior distribution, respectively.
Equation (15) has an analytical solution when all the correlations between reference precipitation $y_{k}\left(\mathbf{u}_{i}\right)$ and observed precipitation $x\left(\mathbf{u}_{i}\right)$ follow the additive error model:

$$
\left\{\begin{array}{l}
\tau_{\mathrm{POST}}\left(\mathbf{u}_{i}\right)=\sum_{k=1}^{m} b_{k}^{2}\left(\mathbf{u}_{i}\right) \tau_{k}\left(\mathbf{u}_{i}\right)+\tau_{\mathrm{ADW}}\left(\mathbf{u}_{i}\right) \\
x_{\mathrm{POST}}\left(\mathbf{u}_{i}\right)=\left[\sum_{k=1}^{m} b_{k}\left(\mathbf{u}_{i}\right) \tau_{k}\left(\mathbf{u}_{i}\right) y_{k}\left(\mathbf{u}_{i}\right)+\tau_{\mathrm{ADW}}\left(\mathbf{u}_{i}\right) x_{\mathrm{ADW}}\left(\mathbf{u}_{i}\right)\right] / \tau_{\mathrm{POST}}\left(\mathbf{u}_{i}\right)
\end{array}\right.
$$

However, if one or more correlations between $y_{k}\left(\mathbf{u}_{i}\right)$ and $x\left(\mathbf{u}_{i}\right)$ follow the multiplicative error model, Eq. (15) cannot be sampled directly. In this case, we adopt Markov chain Monte Carlo (MCMC) sampling methods to estimate the mean and variance of $x\left(\mathbf{u}_{i}\right)$.

\section{Application to the Tibetan Plateau and its surroundings}

\section{a. Study area}

The Tibetan Plateau is located at $25^{\circ}-42^{\circ} \mathrm{N}$ and $77^{\circ}-105^{\circ} \mathrm{E}$ and is the largest and highest plateau in the world. As the source area of many major Asian rivers, such as the Yangtze River, Brahmaputra River, and Lancang River (upstream of the Mekong River; see Fig. 2), the Tibetan Plateau provides valuable freshwater resources for hundreds of millions of people in China and Southeast Asian countries (Immerzeel et al. 2010). Precipitation and frozen water (i.e., snow and glaciers) are the major freshwater sources. In most areas, especially the eastern and southern river basins, precipitation is the most critical component that maintains river streamflow (Cuo and Zhang 2017).

The precipitation on the Tibetan Plateau, which is under the combined and competitive influences of the
East Asian and South Asian monsoons and the westerly belt (Webster et al. 1998; Schiemann et al. 2009; Maussion et al. 2014), has great spatial differences. The mean annual precipitation varies widely from approximately $20 \mathrm{~mm}$ in the northwest to approximately 1900 $\mathrm{mm}$ in the southeast based on gauge observations (Cuo and Zhang 2017). Moreover, the complicated terrain with elevations ranging from 1000 to $7300 \mathrm{~m}$ also influences the precipitation on the Tibetan Plateau. For example, previous studies show that precipitation increases with elevation in the Qilian Mountains area of the northeastern Tibetan Plateau (Wang et al. 2017), while in the lower reaches of the Brahmaputra River of the southern Tibetan Plateau, precipitation decreases with elevation. In particular, the headwaters of the major rivers are located mainly at the edge of the Tibetan Plateau, where elevation changes are severe (such as the upper Yellow River, upper Yangtze River, upper Mekong River, upper Nu River, and upper Brahmaputra River; see Fig. 2). The impact of terrain on precipitation may be significant. In addition to the spatial variability, the precipitation in the Tibetan Plateau also shows strong temporal variability. Based on most gauge observations, more than $70 \%$ of the annual total precipitation occurs 


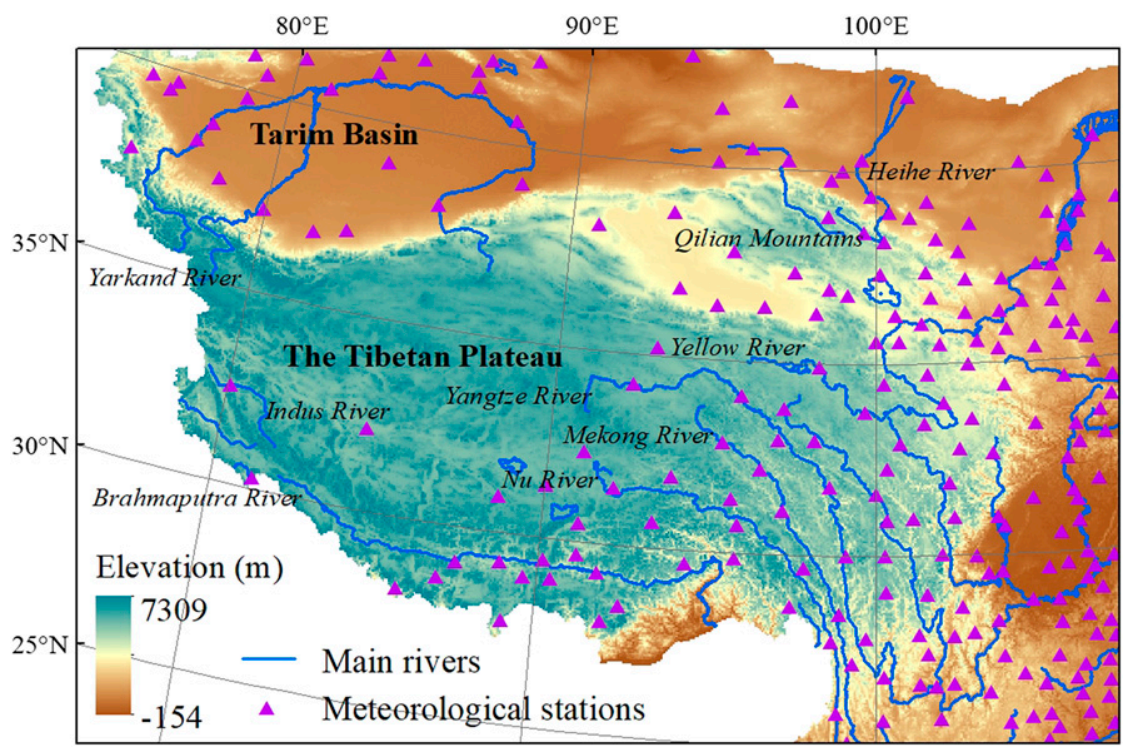

FIG. 2. Study regions and locations of the national meteorological stations.

during the wet season (i.e., May-September; Cuo and Zhang 2017).

\section{b. Data used for the study}

The data used for estimating the precipitation within and around the Tibetan Plateau include a digital elevation model (DEM) and precipitation data. The DEM data were obtained from the Shuttle Radar Topography Mission (SRTM) database (Jarvis et al. 2008), and the precipitation data included gauge observations and two reference precipitation products (TRMM 3B42RT satellite observation and ERA-Interim reanalysis data; Dee et al. 2011; Huffman et al. 2007a).

The gauge data used in this study were the daily precipitation values observed at 227 national meteorological stations on the Tibetan Plateau and its surroundings, which recorded multiple meteorological elements, including precipitation, air temperature, relative humidity, sunshine hours, pan evaporation, atmospheric pressure and wind speed. The daily data were obtained from the China Meteorological Data Sharing Service System (http://data.cma.cn). The daily observational period was in Beijing time from 2000 LT on the previous day to 2000 LT on the current day. Compared to the meteorological stations in other regions in China, those on the Tibetan Plateau are spatially scarce and unevenly located, and most of the stations are located in low-altitude areas, as shown by the solid triangles in Fig. 2. Gauge observations are available when the gauges were established, but different stations have different starting dates. We did not use interpolation if no data were available, and we only used those data that were available.
We used the TRMM Multisatellite Precipitation Analysis (TMPA; Huffman et al. 2007b) near-realtime product (3B42RT) with a temporal resolution of $3 \mathrm{~h}$ and a spatial resolution of $0.25^{\circ}$ as one of the reference precipitation datasets in this study. These data were released in March 2000 and have been widely used in climatic and hydrological studies since being released (Tan and Duan 2017). Although TRMM prediction often overestimates precipitation in mountainous areas, compared to other products, TRMM prediction has been shown to have a better performance overall on the Tibetan Plateau (Tong et al. 2014; Yan et al. 2017). To match the gauge observations, we upscaled the 3-h precipitation to daily values.

Additionally, we utilized ERA-Interim reanalysis data (Dee et al. 2011) as reference precipitation data in addition to the satellite observations. These data were the latest global atmospheric reanalysis data produced by the European Centre for Medium-Range Weather Forecasts (ECMWF). The datasets offer information on many meteorological elements, such as precipitation, air temperature, surface solar radiation and snowfall. ERA-Interim reanalysis data have also been shown to perform well in estimating the climatology of the hydrological cycle over the Tibetan Plateau (Cuo and Zhang 2017). All the data were obtained from ECMWF (https://www.ecmwf.int/). Since the starting times of the daily data are variable, we chose those data that corresponded to our gauge station observation periods (i.e., Beijing time from 2000 LT on the day before to $2000 \mathrm{LT}$ on the current day). The time period of the ERA-Interim dataset was from 1979 to the present. 
We applied precipitation assimilation from 1980 to 2014. We used gauge observation and ERA-Interim data for data assimilation from 1980 to February 2000; beginning in March 2000, we used all three datasets.

In this study, we also used runoff and actual evapotranspiration data of the major river catchments on the Tibetan Plateau to evaluate the assimilated precipitation in different areas from the perspective of water balance. River discharge was recorded at the hydrological stations, and we used these data to calculate the annual runoff. Since the estimation of actual evapotranspiration also contains uncertainty, we used two sets of actual evapotranspiration (ET) products, and their average values were used to estimate the annual evapotranspiration of the river catchments. The first ET product is a global dataset with an 8-km spatial resolution that uses a modified Penman-Monteith approach to calculate ET. The input data include high-resolution satelliteobserved normalized difference vegetation index (NDVI), NCEP-NCAR Reanalysis (NNR) daily surface meteorology, and NASA GEWEX Surface Radiation Budget Release 3.0 solar radiation (Zhang et al. 2010). The second ET product is a machine-learning algorithm-based global dataset with a $0.5^{\circ}$ spatial resolution. The input data include a global monitoring network (FLUXNET), observed landatmosphere exchanges (including water vapor) and meteorological and remote sensing observations (Jung et al. 2010).

\section{c. Preparation of 5-km gridded monthly and daily precipitation}

First, we used bilinear interpolation methods to upscale the DEM and downscale reference precipitation data (i.e., ERA-Interim and TRMM 3B42RT) to the same spatial scale (i.e., $5 \mathrm{~km}$ ) and projection (i.e., Lambert conformal conical projection; Hooijberg 1997). Then, we compared the gauge observations with the collocated reference precipitation data at each gauge location. Since the monthly precipitation is often small (zero or close to zero) during the dry season on the Tibetan Plateau, we chose the additive error model to build the relationship between the ERA-Interim and TRMM 3B42RT precipitation data and gauge observations at both monthly and daily scales. We obtained all the coefficients in Eq. (2), that is, $b_{k}\left(\mathbf{u}_{i}\right)$, $a_{k}\left(\mathbf{u}_{i}\right)$, and $\varepsilon_{k}\left(\mathbf{u}_{i}\right)$, at each grid with gauge stations. At grids without gauge stations, we estimated the coefficients using the ADW interpolation method.

Figures 3 and 4 compare the semivariogram functions without removal of elevation effects and those with removal of elevation effects based on the observed monthly gauge precipitation measurements. The variations in most months are much smaller when the elevation factor is considered. The improvements are more significant in the rainy season from June to August, when the variations
TABLE 1. Indicators to characterize the false alarm and miss rate.

\begin{tabular}{lll}
\hline \hline & \multicolumn{2}{c}{ Estimated precipitation } \\
\cline { 2 - 3 } Gauge observation & \multicolumn{1}{c}{ Precipitation } & No precipitation \\
\hline Precipitation & Hit $(H)$ & Miss $(M)$ \\
No precipitation & False alarm $(F)$ & Correct negative $(C)$ \\
\hline
\end{tabular}

can be reduced by $1000-3000 \mathrm{~m}^{2}$. The results suggest that the modified semivariogram functions are more reasonable. Exponential functions were adopted to fit the semivariogram functions (Fig. 4). The figures show that the variations are greater during the months with higher precipitation (i.e., June-August).

At the daily scale, false alarms (i.e., reference precipitation data show precipitation, but observations show no precipitation) and misses (reference precipitation data show no precipitation, but observations show precipitation) significantly affect the correlation between the reference and observed precipitation values. We used the indices of probability of detection (POD), the false alarm rate (FAR), and the equitable threat score (ETS) to assess the levels of false alarms and misses (Wang et al. 2017). POD represents the ratio of correctly identified precipitation in all the observed precipitation, FAR represents the ratio of identified precipitation that did not actually occur, and ETS is a comprehensive score of false alarms and misses. These indices can be calculated using the following equations:

$$
\begin{aligned}
\mathrm{POD} & =\frac{H}{H+M}, \\
\mathrm{FAR} & =\frac{F}{H+F}, \quad \text { and } \\
\mathrm{ETS} & =\frac{H-\mathrm{He}}{H+M+F-\mathrm{He}},
\end{aligned}
$$

where $\mathrm{He}=(H+M)(H+F) /(H+M+F+C)$ and the other terms are defined in Table 1 . The three indices range from 0 to 1 . For POD and ETS, 1 is best and 0 is worst, while for FAR, 0 is best and 1 is worst.

Table 2 compares the leave-one-out interpolated observations and two reference datasets with daily gauge observations in different elevation zones using various criteria, such as $R^{2}$, POD, ETS, and FAR. The results show that the leave-one-out interpolated observations have the best performance (i.e., highest $R^{2}$, POD, ETS, and lowest FAR). In contrast to TRMM 3B42RT data, ERA-Interim data have a higher correlation with the gauge observations (higher $R^{2}$ ) and a lower FAR and missing rate (higher POD, lower FAR, and higher ETS). Due to the poor correlation between the TRMM 3B42RT data and observed data $\left(R^{2}\right.$ less than 0.05$)$ and the high FAR and missing rate, 

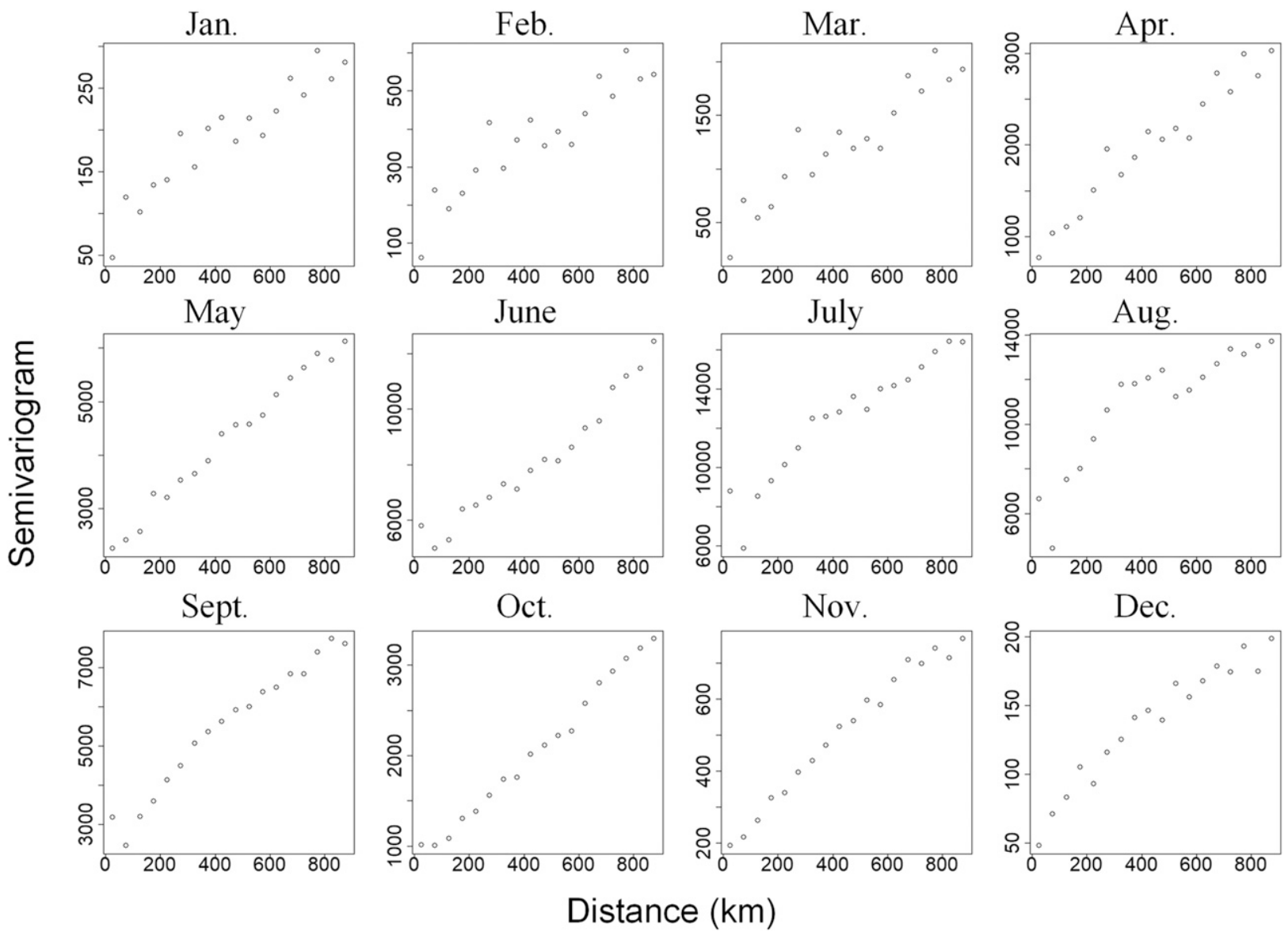

FIG. 3. Semivariogram of monthly precipitation without removal of elevation effects; the dots are the values calculated from gauge observations.

we utilized only ERA-Interim reanalysis data as the reference data at the daily scale. Figure 5 shows the semivariogram functions of the daily data. The ratios of daily precipitation to daily precipitation climatology were used instead of direct daily precipitation. The variations are greater in the cold months (i.e., November-February) because of the lower daily precipitation climatology during these months.

\section{d. Cross-validation method and criteria for evaluation}

We used the leave-one-out cross-validation method to evaluate the precipitation assimilation results (Hofstra et al. 2008), which is commonly utilized to validate the spatial interpolation. The evaluating indices included average absolute error (AAE) and root-mean-square error (RMSE) at the monthly and daily scales. We compared the cross-validation results of our Bayesian method to those based on individual gauge interpolation or individual reference precipitation products (TRMM 3B42RT or ERA-Interim). We evaluated the efficiency of our data assimilation for estimating the spatial distribution of precipitation in mountainous regions. The cross-validation analyses were based on the results after March 2000.

\section{Results and discussion}

\section{a. Validation}

Figure 6 shows the monthly average absolute errors (MAAEs) of the cross-validation results obtained from direct gauge interpolation (i.e., the prior distribution), from two reference datasets (i.e., ERA-Interim reanalysis data and TRMM 3B42RT satellite observations) and from the Bayesian assimilation of gauge measurements and reference data (i.e., the posterior distribution). Comparing Fig. 6a with Figs. 6b and 6c, it is clear that the overall errors in the monthly precipitation estimated by gauge interpolation are far less than the errors from the two reference precipitation products alone. Using our method, the errors in the assimilated precipitation (Fig. 6d) are smaller than those in the gauge interpolation (Fig. 6a). 

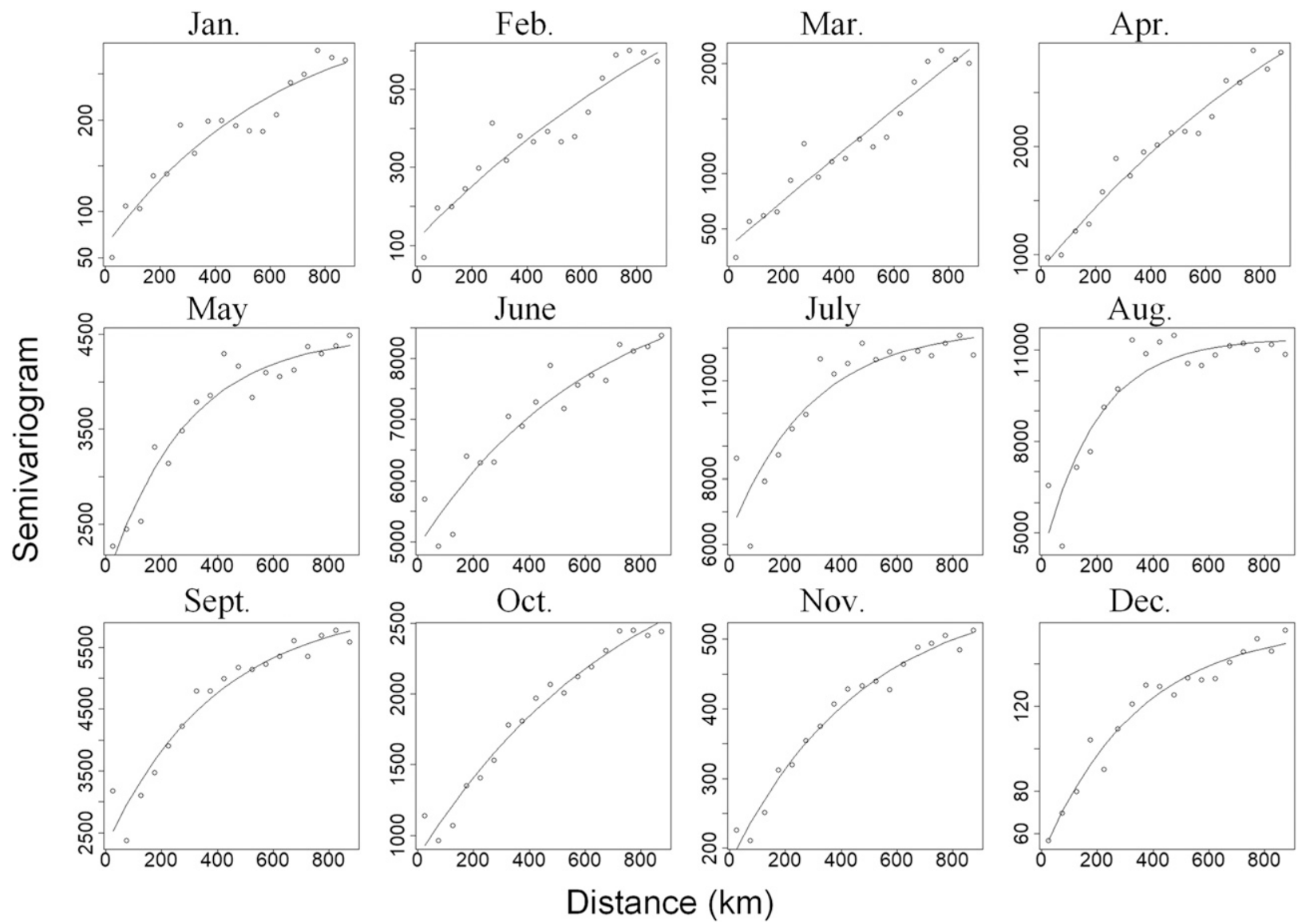

FIG. 4. Semivariogram of monthly precipitation with removal of elevation effects, where the dots are the values calculated from gauges observations and the curves are the fitting exponential functions.

Figures 6e and 6f show the absolute and relative differences in the MAAE between our method (posterior estimates) and direct gauge interpolation (prior distribution). It is clear that the estimates of monthly precipitation in many areas of the Tibetan Plateau are improved using our method. In particular, the improvements are most obvious in the main river source areas on the edge of the Tibetan Plateau. For example, on the northeastern edge (Qilian Mountains) and southeastern edge (the headwater areas of the Yangtze River, $\mathrm{Nu}$ River, and Mekong River), the improvements are the most significant, with reductions in the absolute values of more than $5 \mathrm{~mm}$ and more than $20 \%$ reductions in the relative values of MAAE. In the central and western parts as well as the southern parts (Brahmaputra River basin) of the Tibetan Plateau, the reductions in MAAE are approximately $2-5 \mathrm{~mm}$ in absolute value and $5 \%-20 \%$ in relative value. These results suggest that our method is effective, especially in places where the elevation changes drastically. The results indicate that the consideration of elevation is necessary, and although the ERA-Interim and TRMM 3B42RT data have large absolute deviations, these data still provide useful information for estimating the spatial distribution of monthly precipitation.

Note that not all regions have improved precipitation estimates based on the method. As shown in the figures, the MAAEs in the Tarim basin, located northwest of the Tibetan Plateau, are increased. One possible reason is that we use the same estimated semivariogram across the entire study area. This may lead to overestimates of uncertainties in the prior distribution for regions with little precipitation.

Figure 7 shows the RMSE of the cross-validation results of the monthly precipitation. The results demonstrate that our Bayesian method yields the least errors, and the improvements are the most obvious on the edge of the Tibetan Plateau. Compared to the changes in MAAE, the changes in RMSE between the prior distribution and the posterior distribution are more significant (Figs. 7e,f).

Table 3 summarizes quantitative comparisons of MAAE and monthly RMSE between the values of direct gauge interpolation and the Bayesian method in different elevation zones. The results show that generally, 
TABLE 2. Performance of leave-one-out interpolated observations and data from two references by a comparison with gauge observations at the daily scale in different elevation zones (for POD and ETS, 1 is best and 0 is worst, while for FAR, 0 is best and 1 is worst).

\begin{tabular}{|c|c|c|c|c|c|c|c|c|c|c|c|c|}
\hline \multirow[b]{2}{*}{ Elevation (m) } & \multicolumn{4}{|c|}{$\begin{array}{c}\text { Leave-one-out interpolated } \\
\text { observations }\end{array}$} & \multicolumn{4}{|c|}{ ERA } & \multicolumn{4}{|c|}{ TRMM } \\
\hline & $R^{2}$ & POD & ETS & FAR & $R^{2}$ & POD & ETS & FAR & $R^{2}$ & POD & ETS & FAR \\
\hline$<1000$ & 0.2944 & 0.91 & 0.36 & 0.42 & 0.1270 & 0.79 & 0.22 & 0.50 & 0.0425 & 0.47 & 0.13 & 0.52 \\
\hline $1000-2000$ & 0.2567 & 0.90 & 0.35 & 0.49 & 0.1049 & 0.73 & 0.25 & 0.53 & 0.0254 & 0.46 & 0.12 & 0.64 \\
\hline $2000-3000$ & 0.4013 & 0.93 & 0.34 & 0.45 & 0.2094 & 0.84 & 0.23 & 0.50 & 0.0408 & 0.62 & 0.16 & 0.55 \\
\hline $3000-4000$ & 0.3422 & 0.92 & 0.36 & 0.41 & 0.1721 & 0.89 & 0.25 & 0.47 & 0.0383 & 0.66 & 0.19 & 0.49 \\
\hline$>4000$ & 0.1293 & 0.91 & 0.37 & 0.41 & 0.0642 & 0.93 & 0.25 & 0.49 & 0.0126 & 0.68 & 0.17 & 0.51 \\
\hline
\end{tabular}

the Bayesian estimation yields lower average MAAE and RMSE values in all elevation zones. The improvements are more significant in the high-elevation regions $(>2000 \mathrm{~m})$, with the percentage of reductions in MAAE and RMSE being greater than $10 \%$. This phenomenon is mainly because most of the gauges are located at lower elevations (see the second row in the table). This configuration leads to fewer uncertainties in the prior distribution in low-elevation regions and thus fewer changes in the posterior distribution. In contrast, the sparse distribution of gauges in high-elevation zones results in greater uncertainties in the prior distribution, leading to more significant improvements in the posterior distribution. These results suggest that our method is particularly helpful for improving estimates of precipitation in high mountainous regions.

Figures 8 and 9 show the daily average absolute errors (DAAEs) and daily RMSE of the cross-validation
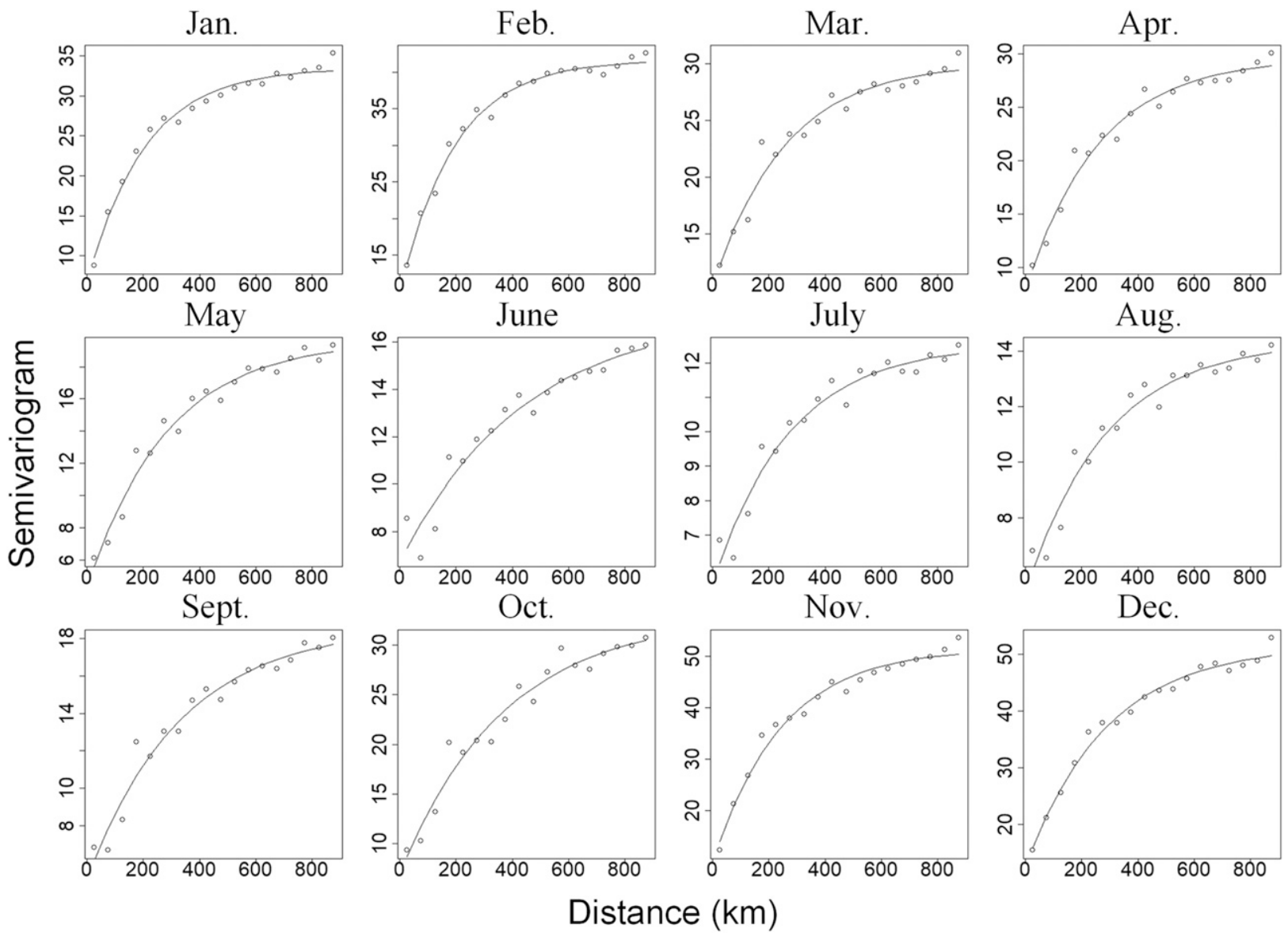

FIG. 5. Semivariogram of the ratios of daily precipitation to daily precipitation climatology, where the dots are the values calculated from gauges observations and the curves are the fitting exponential functions. 
(a) Gauge Interpolation

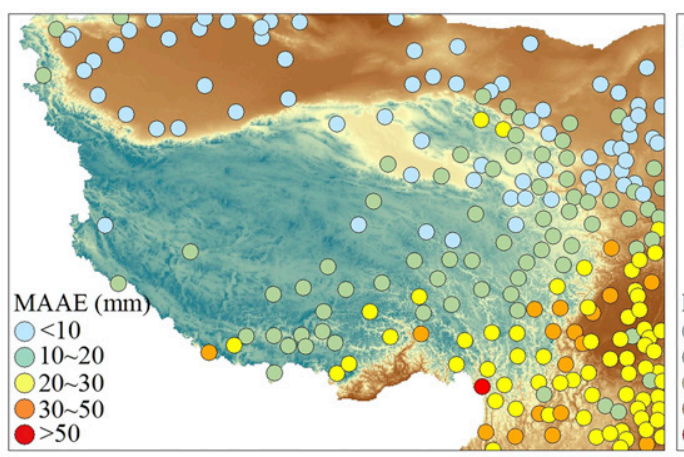

(c) TRMM

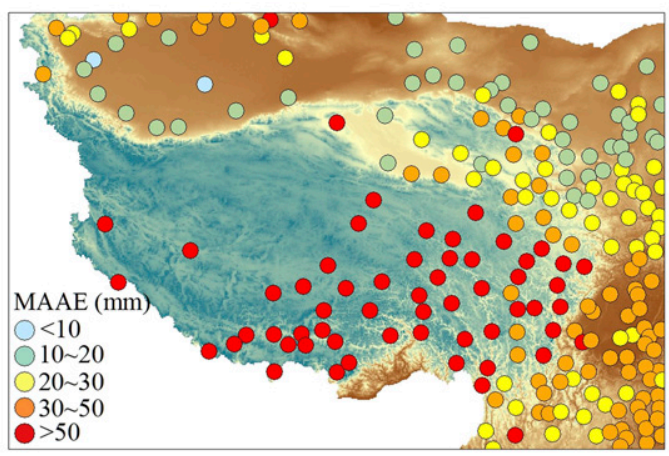

(e) Absolute differences between (a) and (d) (b) ERA

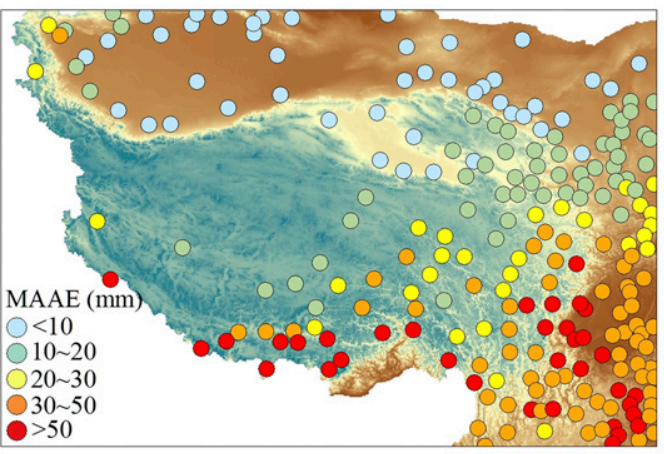

(d) Assimilation Result

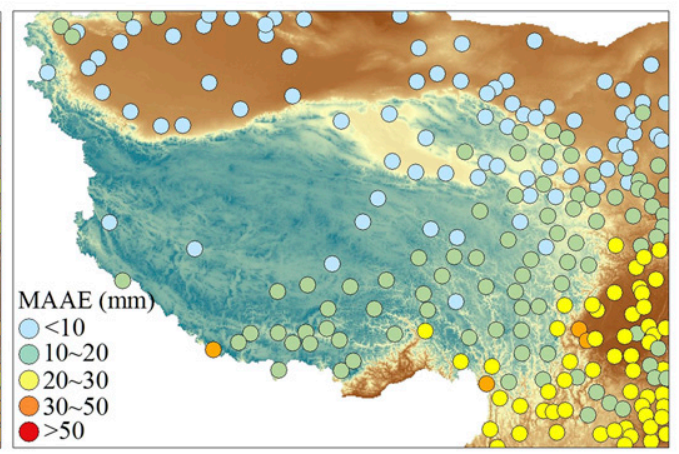

(f) Relative differences between (a) and (d)
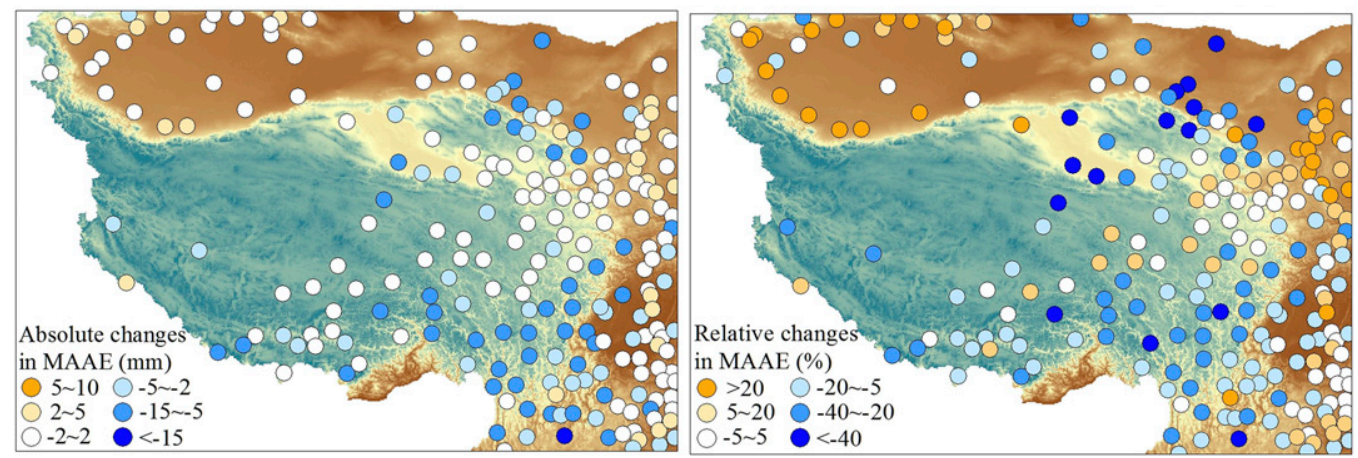

FIG. 6. Monthly average absolute errors (MAAEs) of cross-validation results obtained from (a) direct gauge interpolation, (b) ERA reanalysis data only, (c) TRMM satellite observations only, and (d) the Bayesian method. The (e) absolute and (f) relative differences in MAAE between the prior distribution (direct gauge interpolation) and posterior distribution (assimilation result). The background colors show elevation.

results, respectively. Compared to the uncertainties in gauge interpolation (Figs. 8a, 9a), the uncertainties obtained based on our method (Figs. 8b, 9b) do not significantly decrease. The decrease in uncertainties occurred mainly in the southern and southeastern part of the Tibetan Plateau, while the rest of the area remained basically unchanged. This pattern implies that the improvement resulting from the use of our method at the daily scale is less evident compared to the improvement in the monthly precipitation. This difference likely exists because the correlation between the reference precipitation (ERAInterim) and gauge observations at the daily scale is much worse than the correlation at the monthly scale. In addition, the assimilation of daily precipitation is based on the assimilation results of the monthly precipitation, and thus, overall uncertainties in the daily precipitation are likely higher.

Table 4 shows the differences in DAAE and daily RMSE between the values of direct interpolation and Bayesian assimilation in different elevation zones. 
(a) Gauge Interpolation

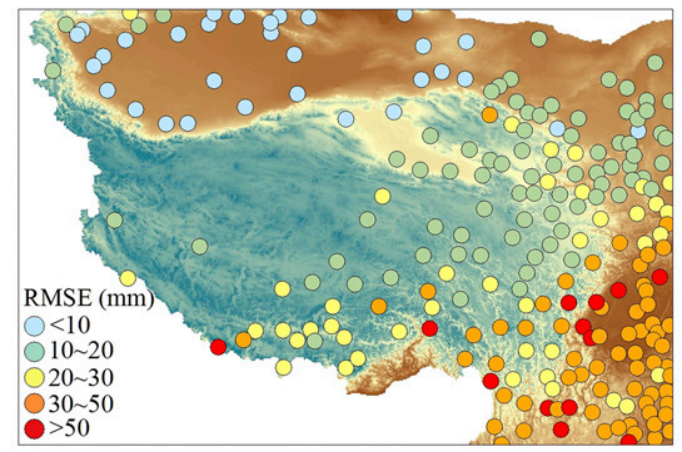

(c) TRMM

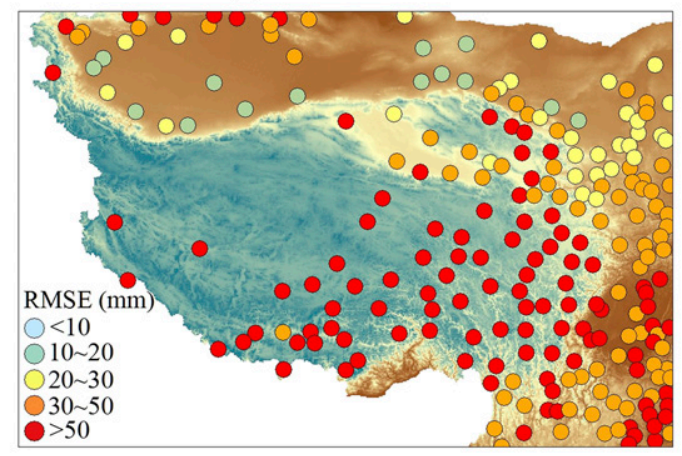

(e) Absolute differences between (a) and (d)

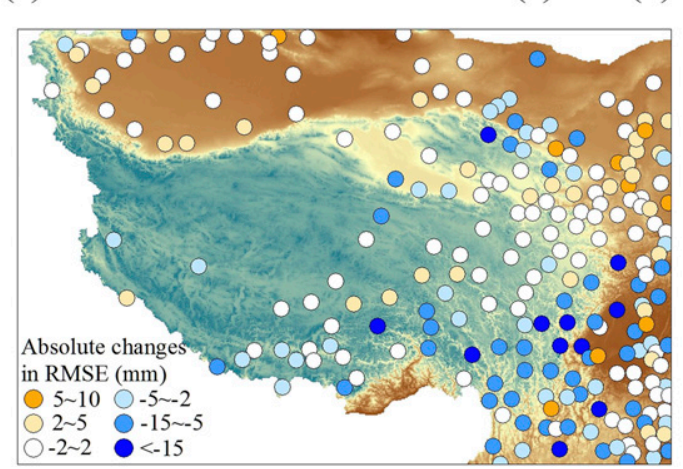

(b) ERA

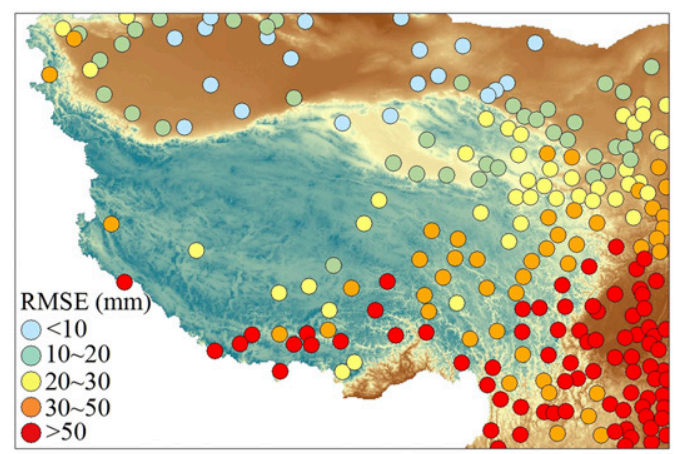

(d) Assimilation Result

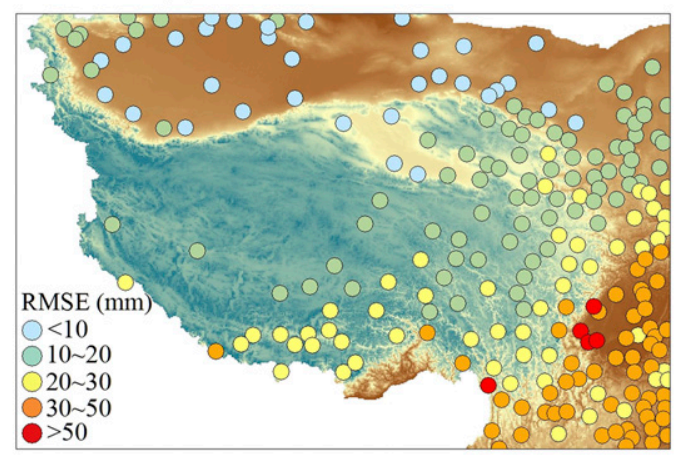

(f) Relative differences between (a) and (d)

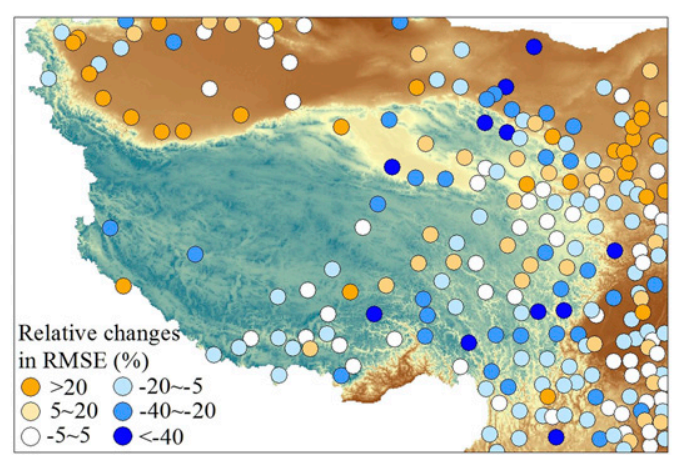

FIG. 7. Monthly RMSE of cross-validation results obtained based on (a) direct gauge interpolation, (b) ERA reanalysis data only, (c) TRMM satellite observations only, and (d) the Bayesian method. The (e) absolute and (f) relative differences in RMSE between the prior distribution (direct gauge interpolation) and posterior distribution (assimilation results).

The results show that Bayesian estimates yield lower average DAAE and RMSE in all elevation zones. The results also show that the improvement at the daily scale is much less than that at the monthly scale, and overall, the relative reduction percentages of DAAE and RMSE are less than $5 \%$.

\section{b. Evaluation of the assimilated precipitation}

Figure 10 shows the spatial distribution of the longterm (2000-14) mean seasonal precipitation obtained using our method. Under the assumption that gauge precipitation observations represent the true precipitation at the gauge location, the spatial distribution of mean precipitation reflects the precipitation variation with elevation. For example, in spring, summer and autumn, precipitation increased with elevation on the northern and northeastern edge of the Tibetan Plateau, while precipitation decreased with elevation in the lower reaches of the Brahmaputra River. The estimation is consistent with the results of many previous studies 
TABLE 3. Differences in MAAE and monthly RMSE between the values from direct gauge interpolation and from Bayesian assimilation for different elevation zones.

\begin{tabular}{|c|c|c|c|c|c|}
\hline Elevation (m) & $<1000 \mathrm{~m}$ & $1000-2000 \mathrm{~m}$ & $2000-3000 \mathrm{~m}$ & $3000-4000 \mathrm{~m}$ & $>4000 \mathrm{~m}$ \\
\hline Number of gauge stations & 42 & 88 & 36 & 39 & 22 \\
\hline MAAE of direct interpolation (mm) & 21.2 & 14.4 & 18.4 & 17.1 & 14.4 \\
\hline MAAE of Bayesian assimilation (mm) & 19.9 & 13.5 & 14.8 & 14.0 & 12.3 \\
\hline Absolute change in MAAE (mm) & -1.3 & -0.9 & -3.5 & -3.2 & -2.2 \\
\hline Relative change in MAAE & $-6 \%$ & $-6 \%$ & $-19 \%$ & $-19 \%$ & $-15 \%$ \\
\hline RMSE of direct interpolation (mm) & 34.2 & 21.6 & 25.8 & 24.9 & 21.0 \\
\hline RMSE of Bayesian assimilation (mm) & 31.3 & 20.6 & 21.8 & 21.5 & 19.1 \\
\hline Absolute change in RMSE (mm) & -2.8 & -1.0 & -3.9 & -3.4 & -2.0 \\
\hline Relative change in RMSE & $-8 \%$ & $-5 \%$ & $-15 \%$ & $-13 \%$ & $-9 \%$ \\
\hline
\end{tabular}

(Wang et al. 2017; Tang et al. 2018). Additionally, we compared the assimilated precipitation with the direct gauge interpolated precipitation, ERA-Interim reanalysis data and TRMM 3B42RT satellite observations (these figures are given in the online supplemental material; see Figs. S1-S3). In general, the spatial pattern of the assimilated precipitation is similar to the direct gauge interpolation results (the prior distribution), while the ERA-Interim reanalysis data and TRMM 3B42RT satellite observation precipitation significantly overestimate the precipitation on the Tibetan Plateau (especially in the southern part of the Tibetan Plateau). The most significant difference between the assimilated precipitation and direct gauge interpolated precipitation is that in the northwestern part of the Tibetan Plateau: the precipitation obtained from direct gauge interpolation is relatively small (lower than those in other parts of the Tibetan Plateau), while the assimilated precipitation is significantly higher in this region. We also compared the assimilated precipitation with the non-real-time TRMM 3B42 (TRMM 3B42V7, see Fig. S4) to evaluate whether our assimilated precipitation results are reasonable. In (a) Gauge Interpolation

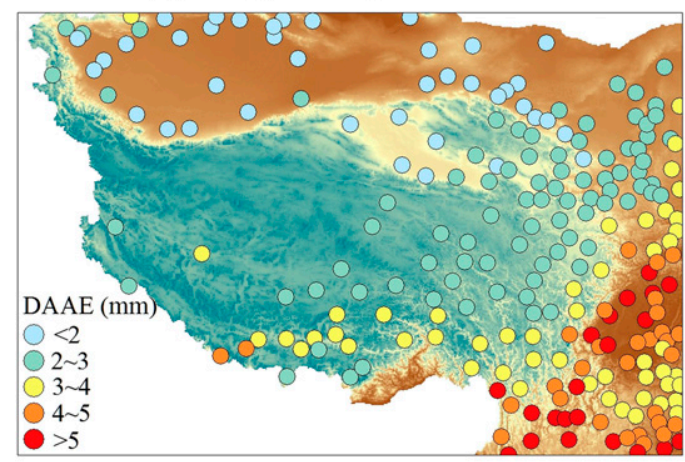

(c) Absolute differences between (a) and (b)

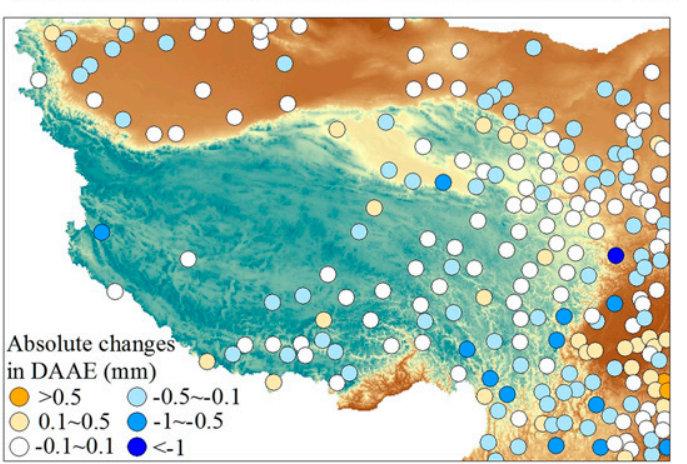

(b) Assimilation Result

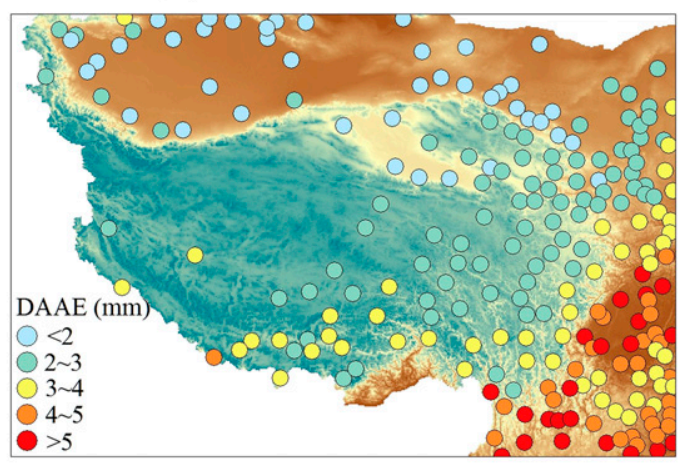

(d) Relative differences between (a) and (b)

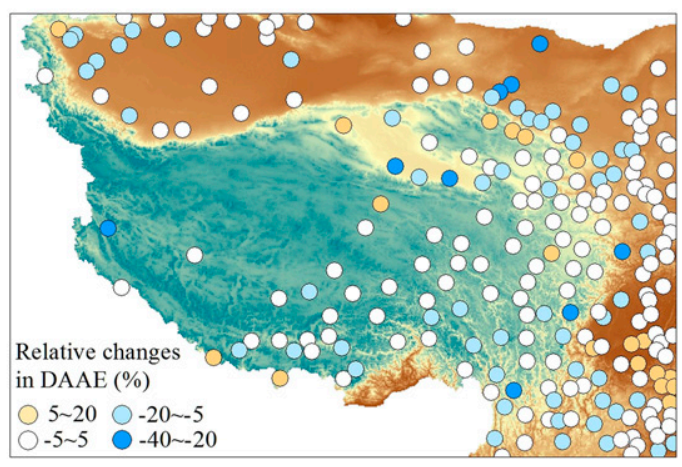

FIG. 8. Daily average absolute errors (DAAEs) of cross-validation results obtained based on (a) direct gauge interpolation and (b) the Bayesian method. The (c) absolute and (d) relative differences in DAAE between the prior distribution (direct gauge interpolation) and posterior distribution (assimilation result). 
(a) Gauge Interpolation

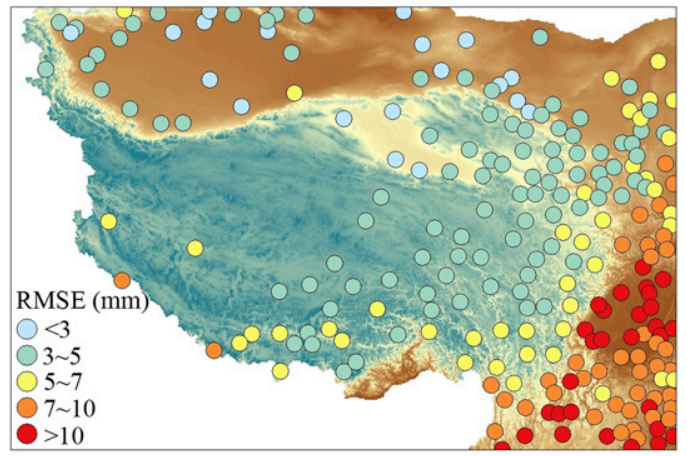

(c) Absolute differences between (a) and (b)

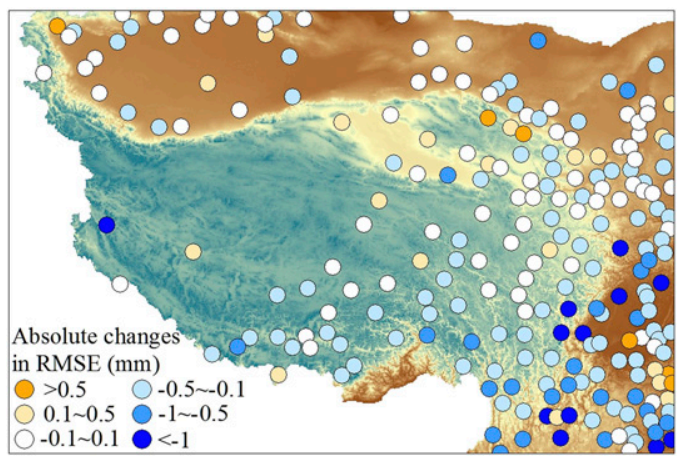

(b) Assimilation Result

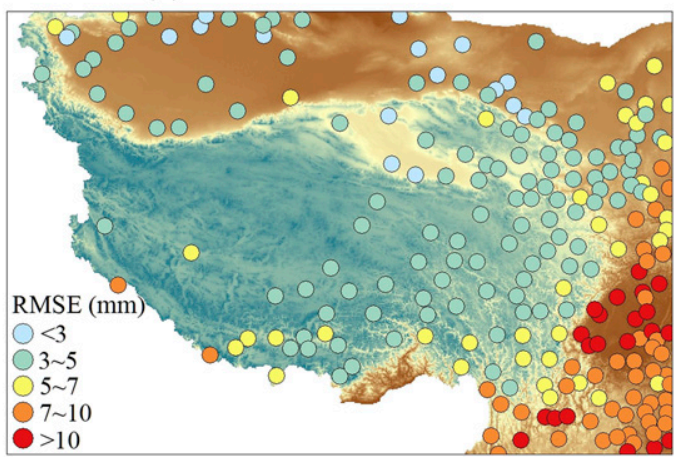

(d) Relative differences between (a) and (b)

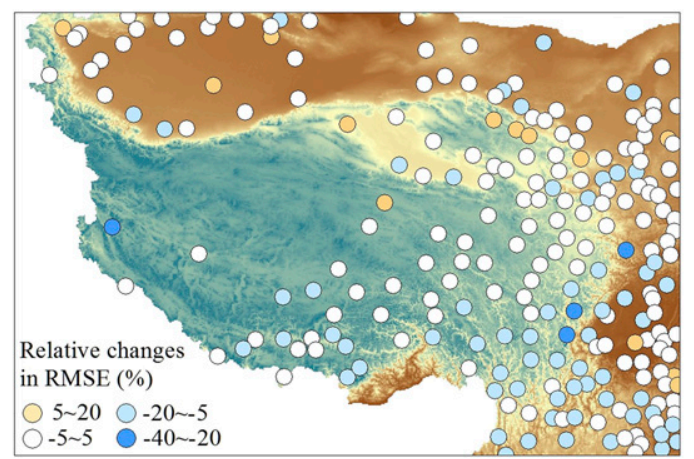

FIG. 9. Daily RMSE of cross-validation results obtained based on (a) direct gauge interpolation and (b) the Bayesian method. The (c) absolute and (d) relative differences in RMSE between the prior distribution (direct gauge interpolation) and posterior distribution (assimilation result).

general, the spatial distributions of the two derived precipitation data are similar. Their main differences are also in the northwestern part of the Tibetan Plateau. Since the TRMM real-time precipitation (i.e., TRMM 3B42RT) is much lower in the region than in the other positions on the Tibetan Plateau (see Fig. S3), the assimilated TRMM 3B42V7 precipitation is low. In contrast, since we used another reference data source (i.e., ERA-Interim data), which shows high precipitation (compared to other regions) in this area (see Fig. S2), our assimilated precipitation is significantly higher in the region, which we feel is more reasonable since this region is the source area of the Yarkant River.

Table 5 compares the catchment-averaged annual precipitation estimated from five different methods with the sum of annual runoff depth and actual evapotranspiration (detailed annual runoff data and annual ET data from the two ET products are shown in the online supplemental material; see Table S1). Compared with the three nonassimilated precipitation data sources (i.e., direct gauge interpolated precipitation, TRMM 3B42RT precipitation and ERA-Interim precipitation), the assimilated

TABLE 4. Differences in DAAE and daily RMSE between the values from direct gauge interpolation and from Bayesian assimilation in different elevation zones.

\begin{tabular}{|c|c|c|c|c|c|}
\hline Elevation (m) & $<1000 \mathrm{~m}$ & $1000-2000 \mathrm{~m}$ & $2000-3000 \mathrm{~m}$ & $3000-4000 \mathrm{~m}$ & $>4000 \mathrm{~m}$ \\
\hline DAAE of direct interpolation (mm) & 4.0 & 3.0 & 3.0 & 2.9 & 2.8 \\
\hline DAAE of Bayesian assimilation (mm) & 4.0 & 2.9 & 2.9 & 2.8 & 2.7 \\
\hline Absolute change in DAAE $(\mathrm{mm})$ & 0.0 & -0.1 & -0.2 & -0.1 & -0.1 \\
\hline Relative change in DAAE & $-1 \%$ & $-4 \%$ & $-5 \%$ & $-2 \%$ & $-2 \%$ \\
\hline RMSE of direct interpolation (mm) & 8.9 & 5.8 & 5.1 & 4.9 & 4.5 \\
\hline RMSE of Bayesian assimilation (mm) & 8.6 & 5.6 & 4.8 & 4.8 & 4.4 \\
\hline Absolute change in RMSE $(\mathrm{mm})$ & -0.3 & -0.2 & -0.2 & -0.1 & -0.2 \\
\hline Relative change in RMSE & $-3 \%$ & $-4 \%$ & $-5 \%$ & $-2 \%$ & $-4 \%$ \\
\hline
\end{tabular}




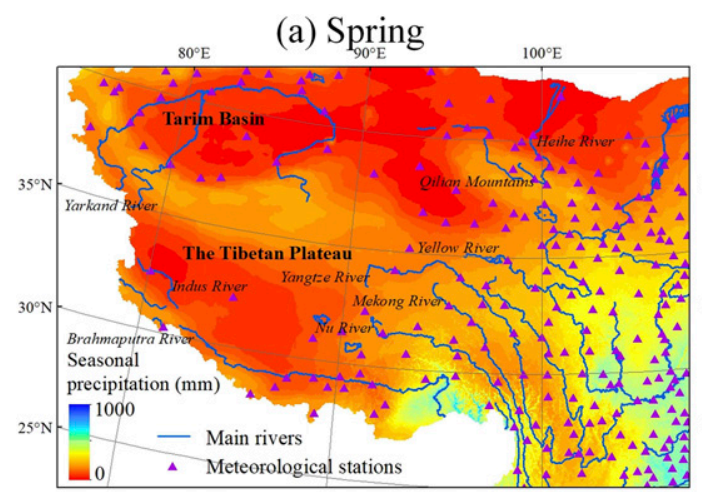

(c) Autumn

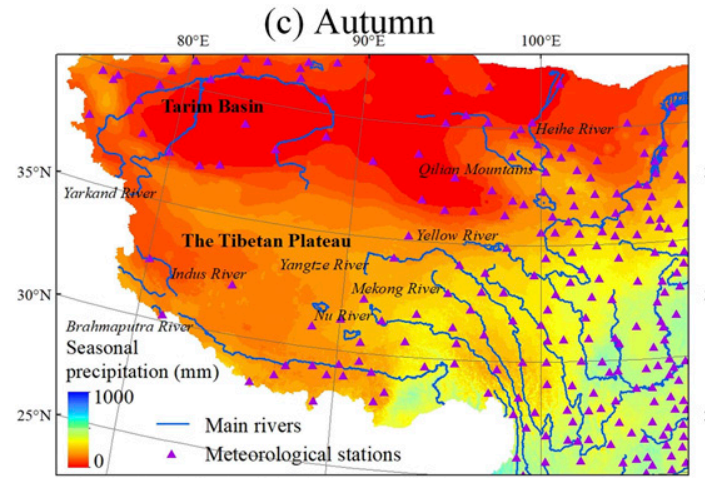

FIG. 10. Spatial distribution of the Bayesian assimilated mean seasonal precipitation. (b) Summer

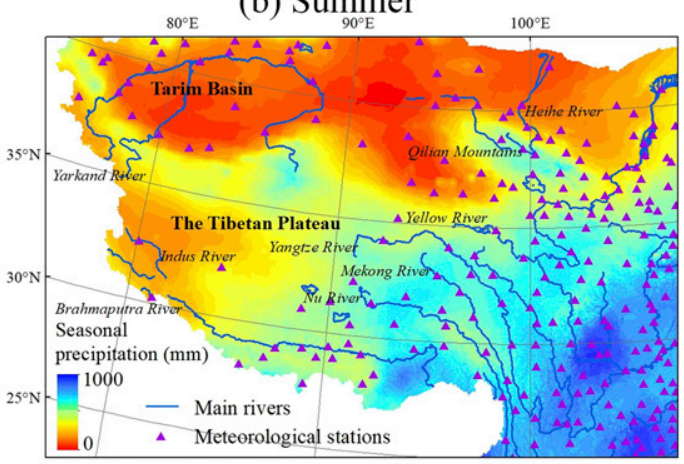

(d) Winter

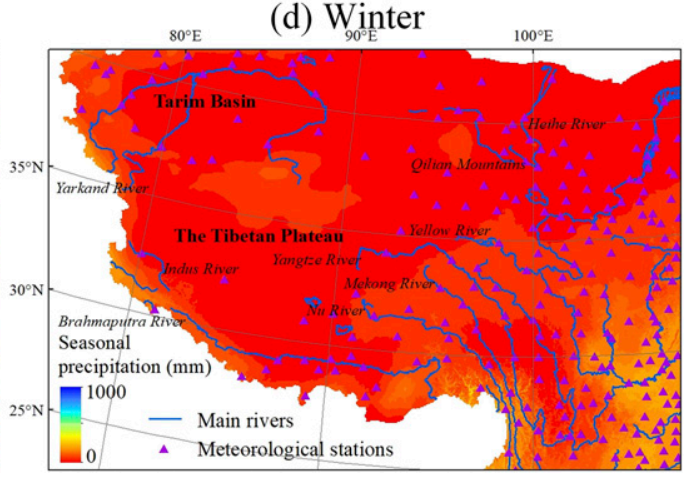

precipitation based on our method is obviously closer to the sum of annual runoff depth and actual evapotranspiration in different catchments. Clearly, the TRMM 3B42RT observed precipitation and ERA-Interim reanalysis data significantly overestimate the precipitation on the Tibetan Plateau. Compared with the directly interpolated precipitation, the assimilated precipitation is higher and closer to the sum of evapotranspiration and runoff in most catchments, indicating that the assimilated precipitation is probably more reasonable. The differences between the directly interpolated precipitation and assimilated precipitation are especially significant in the upper Heihe River, upper Yarkant River, and upper Indus River. In the upper Yarkant River, the ground gauges are very sparse and are all located in plains areas. Although the precipitation-elevation relationship is considered, the gauge observations have difficulty reflecting the precipitation in the upstream mountainous area, which leads to underestimation in this basin. In this case, the addition of the reference precipitation data significantly improved the estimation effect. We also quantitatively compared our assimilated precipitation with TRMM 3B42V7 precipitation in different catchments in the table. Overall, they are similar but not identical. The assimilated precipitation based on our method is closer to the sum of evapotranspiration and runoff in five catchments (i.e., the upper Nu River, upper Lancang River, upper Heihe River, upper Yarkant River, and upper Indus River), while in the other three catchments, the TRMM 3B42V7 precipitation is closer. Due to the large uncertainty in the evaporation data, it is difficult to conclude which estimate is more reasonable. However, we believe that our assimilated precipitation data $\left(243 \mathrm{~mm} \mathrm{yr}^{-1}\right)$ are more reasonable in the Yarkant River basin since the TRMM 3B42V7 precipitation $\left(155 \mathrm{~mm} \mathrm{yr}^{-1}\right)$ is obviously too low, as the annual runoff depth is $139 \mathrm{~mm}$ (see Table S1). Real-time satellite observation data such as TRMM 3B42RT often have large errors in mountainous areas. In areas where ground gauges are very sparse, such as the northwestern Tibetan Plateau (the source of the Yarkant River), the errors are difficult to accurately correct based only on ground gauge observations. In this case, the assimilation of multiple sets of precipitation data may achieve better results.

Figure 11 shows the spatial distribution of the standard error of the long-term monthly averaged precipitation in July, which was obtained using different methods (i.e., direct gauge interpolation, ERA-Interim reanalysis data, TRMM 3B42RT observation, and the Bayesian method). The standard error of the gauge interpolation was obtained based on the ADW method using semivariogram functions. It is clear that the uncertainties were greater in the places farther away from gauge stations (mostly greater than $60 \mathrm{~mm}$; see Fig. 11a). The spatial distributions of 
TABLE 5. Mean annual water balance in different catchments.

\begin{tabular}{|c|c|c|c|c|c|c|}
\hline \multirow[b]{2}{*}{ Basin } & \multicolumn{5}{|c|}{ Annual precipitation (mm) } & \multirow[b]{2}{*}{$\begin{array}{l}\text { Annual total of runoff and } \\
\text { actual evapotranspiration } \\
(\mathrm{mm})\end{array}$} \\
\hline & $\begin{array}{l}\text { TRMM_- } \\
\text { 3B42RT }\end{array}$ & $\begin{array}{l}\text { ERA- } \\
\text { Interim }\end{array}$ & $\begin{array}{l}\text { TRMM_- } \\
\text { 3B42V7 }\end{array}$ & $\begin{array}{c}\text { Gauge interpolated } \\
\text { precipitation }\end{array}$ & $\begin{array}{l}\text { Assimilated } \\
\text { precipitation }\end{array}$ & \\
\hline $\begin{array}{l}\text { Upper } \\
\text { Brahmaputra } \\
\text { River }\end{array}$ & 1575 & 1016 & 619 & 402 & 462 & 602 \\
\hline Upper Nu River & 1807 & 858 & 663 & 551 & 620 & 633 \\
\hline $\begin{array}{l}\text { Upper Lancang } \\
\text { River }\end{array}$ & 1669 & 789 & 576 & 535 & 631 & 603 \\
\hline $\begin{array}{l}\text { Upper Yangtze } \\
\text { River }\end{array}$ & 1279 & 601 & 396 & 386 & 401 & 370 \\
\hline $\begin{array}{l}\text { Upper Yellow } \\
\text { River }\end{array}$ & 1041 & 711 & 519 & 507 & 603 & 538 \\
\hline Upper Heihe River & 955 & 312 & 440 & 281 & 466 & 471 \\
\hline $\begin{array}{l}\text { Upper Yarkant } \\
\text { River }\end{array}$ & 439 & 327 & 155 & 77 & 243 & 371 \\
\hline Upper Indus River & 1053 & 553 & 427 & 129 & 247 & 266 \\
\hline
\end{tabular}

the standard errors for ERA-Interim and TRMM 3B42RT data were spatially interpolated from gauge values, which were obtained based on the additive error model using the ADW interpolation method. The standard errors based on the two datasets were relatively small $(0-40 \mathrm{~mm})$ in the basin area located north of the Tibetan Plateau (e.g., Tarim basin), where the precipitation is very low. However, the standard errors were much larger on the Tibetan Plateau, especially in the southern part of the Tibetan Plateau, where the standard errors were greater than $70 \mathrm{~mm}$. Compared with the above three methods (Figs. 11a-c), the standard error based on our method (Fig. 11d) was much smaller. The standard error was less than $50 \mathrm{~mm}$ in the entire study area, indicating a significant improvement. The spatial distribution of the standard error is similar to that of the cross-validation results shown in Fig. 7d, indicating that the spatial distribution is reasonable. In addition, the spatial distribution pattern of the standard error is similar to the mean monthly precipitation (Fig. 10), and the uncertainty is greater when the precipitation is higher. In the northwestern Tibetan Plateau, which experiences less precipitation, the standard error is basically within $20 \mathrm{~mm}$, while in the northeastern, eastern and southern parts of the Tibetan Plateau, where the precipitation is relatively higher, the standard error is between 20 and $30 \mathrm{~mm}$.

\section{c. Discussion}

In this study, the sources of uncertainty in precipitation assimilation include gauge measurement errors, reference precipitation data errors, estimated parameter errors in the correlation between the reference precipitation and gauge observations, and spatial interpolation errors in the gauge observations.
We considered the gauge observation as the true values. In practice, gauge measurements are subject to multiple sources of uncertainty due to gauge types, terrain conditions, and precipitation types (rain or snow). For example, the gauge observations may have a low bias in precipitation due to undercatch of the snowfall. The precipitation gauge types include both nonrecording type (i.e., manual observation, mainly before 2000) and tipping-bucket type (mainly after 2000; Ren et al. 2007). The gauge measurements include different types of precipitation, such as rainfall, snow (including sleet and snow), microprecipitation, and pure mist and dew. When measuring snowfall, the snow was weighed on a platform scale or measured using a measuring cup after the snow was melted (see China Meteorological Administration 2003). On the Tibetan Plateau, snowfall contributes to $\sim 30 \%-40 \%$ (viz., 100-200 $\mathrm{mm}$ ) of the annual precipitation (Wang et al. 2016). Ye et al. (2007) estimated the precipitation measurement errors of the National Meteorological Stations and found that the annual precipitation on the Tibetan Plateau was likely to be underestimated by $25-50 \mathrm{~mm}$. This value is much smaller than the overestimation of ERA-Interim and TRMM 3B42RT data. This difference justifies our assumption of gauge observation as the true value in the case study area.

The correlation between satellite or model precipitation and gauge observations is dependent on spatial and time scales, regional variability, the metric used, and the precipitation types. In terms of spatial scales, we use observations at a single gauge station to represent their values over the surrounding $5-\mathrm{km}$ grid cell. We use this assumption mainly for two reasons. The first reason is that compared to satellite precipitation or modelsimulated precipitation, ground-based observation has 
(a) Gauge Interpolation

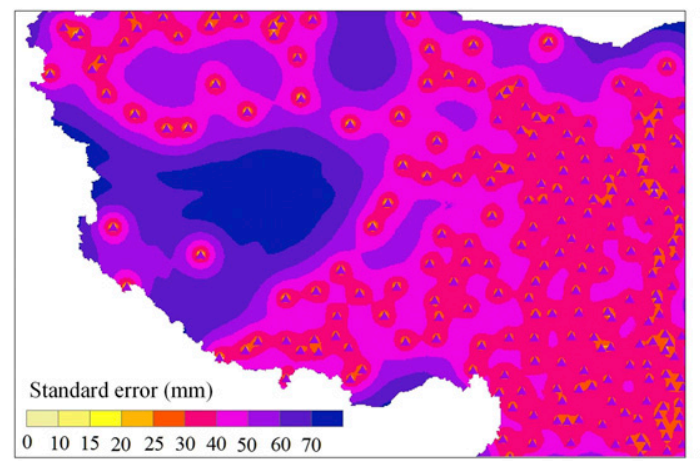

(c) TRMM

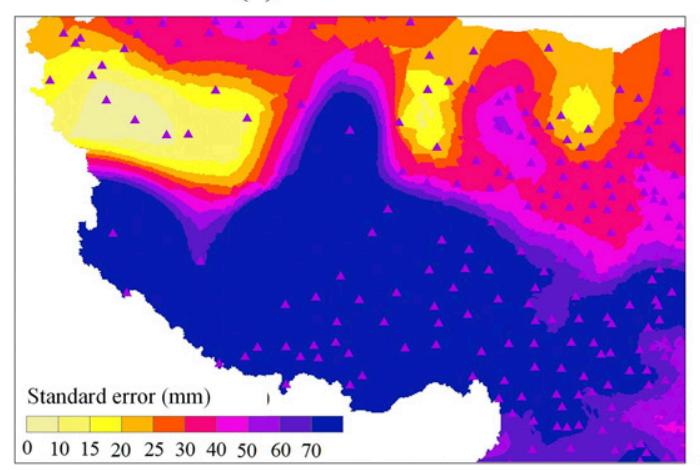

(b) ERA

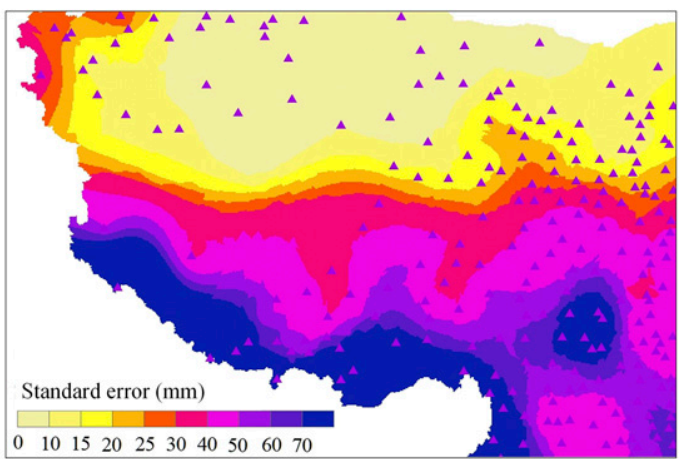

(d) Assimilation Result

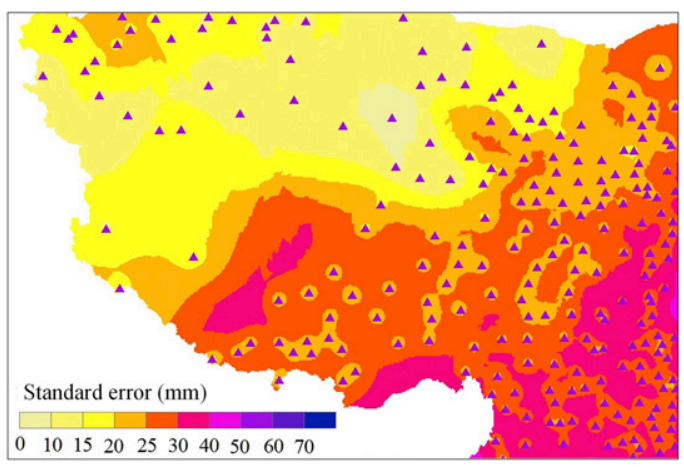

FIG. 11. Spatial distribution of the standard error of the long-term monthly averaged precipitation in July based on (a) direct gauge interpolation, (b) ERA reanalysis data, (c) TRMM satellite observations, and (d) the Bayesian method.

many fewer errors, and the second reason at the current stage is that we do not have effective ways to estimate the errors. We acknowledge this assumption is not ideal and could cause uncertainties. If the reference precipitation products have high accuracy and good correlations with the gauge observations, the precipitation assimilation results will be close to the values of the reference precipitation. Conversely, if the reference precipitation has large biases and is weakly correlated with gauge observations, the assimilated precipitation will be closer to the gauge interpolation results (i.e., prior distribution). In the case study, since the correlation between ERA-Interim precipitation and gauge observations is poor at the daily scale, the improvement resulting from the use of our method at the daily scale is less significant compared to that for the monthly precipitation. In addition, the spatial interpolation of parameters in the addition or multiplication model [i.e., the parameters in Eq. (2)] may also cause uncertainties. These parameters are likely to be affected by terrain. Since ground gauges are often located in low areas, we have very limited data to estimate the changes in these parameters as a function of terrain. As a result, we only smoothly interpolated these parameters.
Consequently, highly accurate reference precipitation products can significantly improve the precipitation assimilation results using the proposed method. For example, Global Precipitation Measurement (GPM) satellite precipitation products with higher accuracy and better performance in mountainous areas may be utilized for future precipitation assimilation. Local RCM simulation results or radar observations may also be used in studies in middle- or small-scale catchments. In addition, the choice of additive error models over multiplicative error models may affect the results. The model choice should be analyzed on a case-by-case basis.

In the proposed method, the gauge interpolation uncertainty is estimated by the semivariogram function. According to the function form, the uncertainty is only related to the distance and elevation but not the precipitation magnitude. In the application to the Tibetan Plateau in this study, the function was estimated based on observations at all 227 stations in the entire study area. As shown in Fig. 11a, the spatial distribution of uncertainty does not reflect the phenomenon that the uncertainty is greater where the precipitation is higher. This is a limitation of the current method. For example, the monthly precipitation is scarce (near zero, see Fig. 10) 
(a) Absolute differences in MAAE

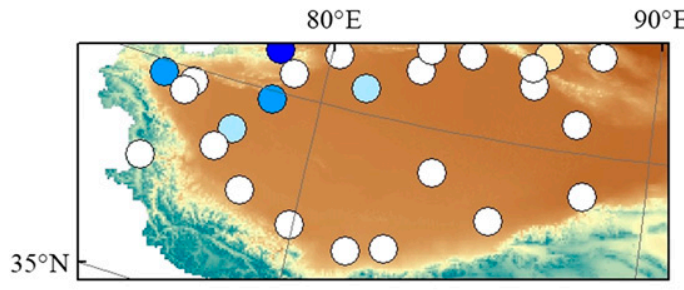

(c) Absolute differences in RMSE $80^{\circ} \mathrm{E}$

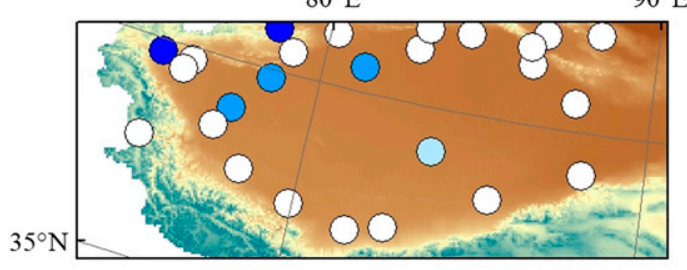

Absolute changes in MAAE and RMSE (mm)

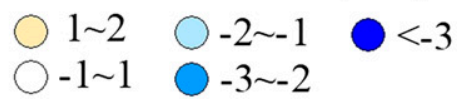

(b) Relative differences in MAAE

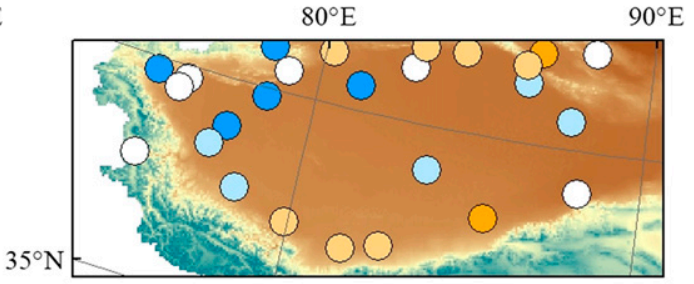

(d) Relative differences in RMSE $80^{\circ} \mathrm{E}$

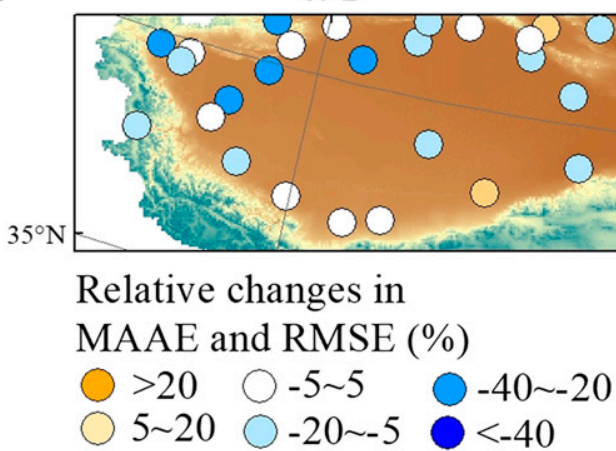

FIG. 12. Differences in MAAE and RMSE between the prior distribution (direct gauge interpolation) and posterior distribution (assimilation results) for the monthly precipitation in the Tarim basin, located north of the Tibetan Plateau.

in the Tarim basin in July, while the uncertainties in the monthly precipitation are still $30-60 \mathrm{~mm}$. This uncertainty may make the posterior distribution worse than the prior distribution in the area, as we discussed in section $4 \mathrm{a}$. To solve this problem without changing the semivariogram function form, we can attempt to divide the entire region into several subregions based on the precipitation magnitude or climate type and estimate the semivariogram functions separately for different subregions. As a result, the semivariogram functions in different regions may be different.

As an example, we assimilated the precipitation in the Tarim basin, where the posterior distribution is poorer than the prior distribution when using one semivariogram function in the entire study area. The new semivariogram is only estimated based on the observations of 26 gauges within the subregion. Figure 12 shows the differences in the crossvalidation results between the posterior distribution and prior distribution. The results show that the uncertainties in the assimilated precipitation are smaller than those of the direct gauge interpolated precipitation. These results suggest that the use of different semivariograms for different subregions can be an approach to effectively reduce uncertainties caused by a single semivariogram for the entire region.

\section{Conclusions}

We developed a multiscale Bayesian model to estimate monthly and daily precipitation in mountainous areas by combining gauge observations with reference precipitation products. With the use of data from 227 national meteorological stations, TRMM 3B42RT satellites, and ERA-Interim reanalysis, our method can provide 5-km-resolution gridded monthly and daily precipitation data from 1980 to 2014. A summary of our main findings is as follows:

1) The developed method effectively utilized the spatially distributed precipitation information from reference precipitation data to improve the estimates of precipitation in mountainous areas where observation stations are typically sparse. The use of the precipitation-elevation relationship is critical for reducing uncertainties in estimating mountain precipitation.

2) Cross-validation results show that the estimation errors from our method are lower than those obtained from either the direct gauge interpolation or the reference precipitation product alone. This finding suggests that our method is effective in combining the two different scales of information for estimating the spatial distribution of precipitation in mountainous areas. In general, our method improves upon the precipitation estimates on the Tibetan Plateau. The improvements are more significant in the main river source areas on the edge of the Tibetan Plateau, indicating that the consideration of terrain effects is 
reasonable and useful. Moreover, the improvements are greater in the high-elevation regions (the percentages of the reductions in MAAE and monthly RMSE are greater than $10 \%$ ) than in the lowerelevation regions $(\sim 0 \%-10 \%)$. This finding implies that assimilation is more useful in areas where ground gauges are sparse.

3) According to the assimilated precipitation spatial distribution on the Tibetan Plateau based on our method, the precipitation variations with elevation are consistent with those reported in many previous studies. The uncertainties in the assimilated precipitation are smaller than those of gauge interpolations and reference precipitation.

4) The proposed method is applicable to other regions, and it is particularly useful for mountainous watersheds where the ground meteorological stations are sparse and the precipitation is considerably influenced by terrain, such as the main river source areas on the edge of the Tibetan Plateau.

Acknowledgments. This research was supported by the National Natural Science Foundation of China (NSFC Projects 91425303 and 41630856) and the Strategic Priority Research Program of Chinese Academy of Sciences, Grant XDA20100103.

\section{REFERENCES}

Alemohammad, S. H., D. B. McLaughlin, and D. Entekhabi, 2015: Quantifying precipitation uncertainty for land data assimilation applications. Mon. Wea. Rev., 143, 3276-3299, https:// doi.org/10.1175/MWR-D-14-00337.1.

Barillec, R., and D. Cornford, 2009: Data assimilation for precipitation nowcasting using Bayesian inference. Adv. Water Resour., 32, 1050-1065, https://doi.org/10.1016/j.advwatres.2008.09.004.

Basist, A., G. D. Bell, and V. Meentemeyer, 1994: Statistical relationships between topography and precipitation patterns. J. Climate, 7, 1305-1315, https://doi.org/10.1175/1520-0442(1994) 007<1305:SRBTAP $>2.0 . C O ; 2$.

Bianchi, B., P. Jan Van Leeuwen, R. J. Hogan, and A. Berne, 2013: A variational approach to retrieve rain rate by combining information from rain gauges, radars, and microwave links. J. Hydrometeor., 14, 1897-1909, https://doi.org/10.1175/JHMD-12-094.1.

Chen, J., S. Hubbard, and R. Yoram, 2001: Estimating the hydraulic conductivity at the South Oyster Site from geophysical tomographic data using Bayesian techniques based on the normal linear regression model. Water Resour. Res., 37, 1603-1613, https://doi.org/10.1029/2000WR900392.

China Meteorological Administration, 2003: Specifications for Surface Meteorological Observation. China Meteorological Press, 151 pp.

Cressie, N., 1993: Statistics for Spatial Data. Rev. Ed. WileyInterscience, $928 \mathrm{pp}$.

Cuo, L., and Y. Zhang, 2017: Spatial patterns of wet season precipitation vertical gradients on the Tibetan Plateau and the surroundings. Sci. Rep., 7, 5057, https://doi.org/10.1038/ s41598-017-05345-6.

Daly, C., R. P. Neilson, and D. L. Phillips, 1994: A statisticaltopographic model for mapping climatological precipitation over mountainous terrain. J. Appl. Meteor., 33, 140-158, https:// doi.org/10.1175/1520-0450(1994)033<0140:ASTMFM >2.0.CO;2.

—, M. Halbleib, J. I. Smith, W. P. Gibson, M. K. Doggett, G. H. Taylor, J. Curtis, and P. P. Pasteris, 2008: Physiographically sensitive mapping of climatological temperature and precipitation across the conterminous United States. Int. J. Climatol., 28, 2031-2064, https://doi.org/10.1002/joc.1688.

Dee, D. P., and Coauthors, 2011: The ERA-Interim reanalysis: Configuration and performance of the data assimilation system. Quart. J. Roy. Meteor. Soc., 137, 553-597, https://doi.org/ 10.1002/qj.828.

Delhomme, J. P., 1978: Kriging in the hydrosciences. Adv. Water Resour., 1, 251-266, https://doi.org/10.1016/0309-1708(78) 90039-8.

Fowler, H. J., S. Blenkinsop, and C. Tebaldi, 2007: Linking climate change modelling to impacts studies: Recent advances in downscaling techniques for hydrological modelling. Int. J. Climatol., 27, 1547-1578, https://doi.org/10.1002/joc.1556.

Giovannettone, J. P., and A. P. Barros, 2009: Probing regional orographic controls of precipitation and cloudiness in the central Andes using satellite data. J. Hydrometeor., 10,167-182, https:// doi.org/10.1175/2008JHM973.1.

Gottschalck, J., J. Meng, M. Rodell, and P. Houser, 2005: Analysis of multiple precipitation products and preliminary assessment of their impact on global land data assimilation system land surface states. J. Hydrometeor., 6, 573-598, https://doi.org/ 10.1175/JHM437.1.

Guan, H., J. L. Wilson, and O. Makhnin, 2005: Geostatistical mapping of mountain precipitation incorporating autosearched effects of terrain and climatic characteristics. J. Hydrometeor., 6 , 1018-1031, https://doi.org/10.1175/JHM448.1.

,-- , and H. Xie, 2009: A cluster-optimizing regressionbased approach for precipitation spatial downscaling in mountainous terrain. J. Hydrol., 375, 578-588, https://doi.org/ 10.1016/j.jhydrol.2009.07.007.

Haberlandt, U., 2007: Geostatistical interpolation of hourly precipitation from rain gauges and radar for a large-scale extreme rainfall event. J. Hydrol., 332, 144-157, https://doi.org/10.1016/ j.jhydrol.2006.06.028.

Hofstra, N., and M. New, 2009: Spatial variability in correlation decay distance and influence on angular-distance weighting interpolation of daily precipitation over Europe. Int. J. Climatol., 29, 1872-1880, https://doi.org/10.1002/joc.1819.

_ M. Haylock, M. New, P. Jones, and C. Frei, 2008: Comparison of six methods for the interpolation of daily, European climate data. J. Geophys. Res., 113, D21110, https://doi.org/10.1029/ 2008JD010100.

Hooijberg, M., 1997: Lambert's conformal conical projection. Practical Geodesy, Springer, 133-156.

Huffman, G. J., and Coauthors, 2007a: The TRMM Multisatellite Precipitation Analysis (TMPA): Quasi-global, multiyear, combinedsensor precipitation estimates at fine scales. J. Hydrometeor., $\mathbf{8}$, 38-55, https://doi.org/10.1175/JHM560.1.

$\longrightarrow$, R. Adler, D. Bolvin, and E. Nelkin, 2007b: TRMM Multisatellite Precipitation Analysis (TMPA). J. Hydrometeor., 8, 38, https://doi.org/10.1175/JHM560.1.

Immerzeel, W. W., M. M. Rutten, and P. Droogers, 2009: Spatial downscaling of TRMM precipitation using vegetative response on the Iberian Peninsula. Remote Sens. Environ., 113, 362-370, https://doi.org/10.1016/j.rse.2008.10.004. 
- , L. P. H. van Beek, and M. F. P. Bierkens, 2010: Climate change will affect the Asian water towers. Science, $\mathbf{3 2 8}$, 1382-1385, https://doi.org/10.1126/science.1183188.

Jarvis, A., H. I. Reuter, A. Nelson, and E. Guevara, 2008: Holefilled SRTM for the globe version 4. CGIAR-CSI SRTM 90m Database, http://srtm.csi.cgiar.org/.

Jia, S., W. Zhu, A. Lü, and T. Yan, 2011: A statistical spatial downscaling algorithm of TRMM precipitation based on NDVI and DEM in the Qaidam Basin of China. Remote Sens. Environ., 115, 3069-3079, https://doi.org/10.1016/j.rse.2011.06.009.

Joyce, R. J., J. E. Janowiak, P. A. Arkin, and P. Xie, 2004: CMORPH: A method that produces global precipitation estimates from passive microwave and infrared data at high spatial and temporal resolution. J. Hydrometeor., 5, 487-503, https:// doi.org/10.1175/1525-7541(2004)005<0487:CAMTPG>2.0.CO;2.

Jung, M., and Coauthors, 2010: Recent decline in the global land evapotranspiration trend due to limited moisture supply. Nature, 467, 951-954, https://doi.org/10.1038/nature09396.

Kaptué, A. T., N. P. Hanan, L. Prihodko, and J. A. Ramirez, 2015: Spatial and temporal characteristics of rainfall in Africa: Summary statistics for temporal downscaling. Water Resour. Res., 51, 2668-2679, https://doi.org/10.1002/2014WR015918.

Kavetski, D., G. Kuczera, and S. W. Franks, 2006: Bayesian analysis of input uncertainty in hydrological modeling: 1 . Theory. Water Resour. Res., 42, W03407, https://doi.org/ 10.1029/2005WR004368

Kingsmill, D. E., P. J. Neiman, F. M. Ralph, and A. B. White, 2006: Synoptic and topographic variability of Northern California precipitation characteristics in landfalling winter storms observed during CALJET. Mon. Wea. Rev., 134, 2072-2094, https://doi.org/10.1175/MWR3166.1.

Kirshbaum, D. J., and D. R. Durran, 2005a: Atmospheric factors governing banded orographic convection. J. Atmos. Sci., 62, 3758-3774, https://doi.org/10.1175/JAS3568.1.

- and $-2005 \mathrm{~b}$ : Observations and modeling of banded orographic convection. J. Atmos. Sci., 62, 1463-1479, https:// doi.org/10.1175/JAS3417.1.

Kitanidis, P. K., 1997: Introduction to Geostatistics. Cambridge University Press, $272 \mathrm{pp}$

Li, M., D. Yang, J. Chen, and S. S. Hubbard, 2012: Calibration of a distributed flood forecasting model with input uncertainty using a Bayesian framework. Water Resour. Res., 48, W08510, https://doi.org/10.1029/2010WR010062.

Li, Z., 2015: Multi-source precipitation observations and fusion for hydrological applications in the Yangtze River Basin. Ph.D. thesis, Tsinghua University, $167 \mathrm{pp}$

, D. Yang, and Y. Hong, 2013: Multi-scale evaluation of highresolution multi-sensor blended global precipitation products over the Yangtze River. J. Hydrol., 500, 157-169, https:// doi.org/10.1016/j.jhydrol.2013.07.023.

$\_,-,-$J. Zhang, and Y. Qi, 2014: Characterizing spatiotemporal variations of hourly rainfall by gauge and radar in the mountainous Three Gorges Region. J. Appl. Meteor. Climatol., 53, 873-889, https://doi.org/10.1175/JAMC-D13-0277.1.

Lloyd, C. D., 2005: Assessing the effect of integrating elevation data into the estimation of monthly precipitation in Great Britain. J. Hydrol., 308, 128-150, https://doi.org/10.1016/ j.jhydrol.2004.10.026.

Lundquist, J. D., J. R. Minder, P. J. Neiman, and E. Sukovich, 2010: Relationships between barrier jet heights, orographic precipitation gradients, and streamflow in the northern Sierra Nevada. J. Hydrometeor., 11, 1141-1156, https://doi.org/ 10.1175/2010JHM1264.1.
Ly, S., C. Charles, and A. Degré, 2011: Geostatistical interpolation of daily rainfall at catchment scale: The use of several variogram models in the Ourthe and Ambleve catchments, Belgium. Hydrol. Earth Syst. Sci., 15, 2259-2274, https:// doi.org/10.5194/hess-15-2259-2011.

Mass, C., N. Johnson, M. Warner, and R. Vargas, 2015: Synoptic control of cross-barrier precipitation ratios for the Cascade Mountains. J. Hydrometeor., 16, 1014-1028, https://doi.org/ 10.1175/JHM-D-14-0149.1.

Maussion, F., D. Scherer, T. Mölg, E. Collier, J. Curio, and R. Finkelnburg, 2014: Precipitation seasonality and variability over the Tibetan Plateau as resolved by the High Asia Reanalysis. J. Climate, 27, 1910-1927, https://doi.org/10.1175/ JCLI-D-13-00282.1.

New, M., M. Hulme, and P. Jones, 2000: Representing twentiethcentury space-time climate variability. Part II: Development of 1901-96 monthly grids of terrestrial surface climate. J. Climate, 13, 2217-2238, https://doi.org/10.1175/1520-0442(2000)013<2217: RTCSTC $>2.0 . \mathrm{CO} ; 2$.

Newman, A. J., and Coauthors, 2015: Gridded ensemble precipitation and temperature estimates for the contiguous United States. J. Hydrometeor., 16, 2481-2500, https://doi.org/10.1175/ JHM-D-15-0026.1.

Nykanen, D. K., E. Foufoulageorgiou, and W. M. Lapenta, 2001: Impact of small-scale rainfall variability on larger-scale spatial organization of land atmosphere fluxes. J. Hydrometeor., 2, 105-121, https://doi.org/10.1175/1525-7541(2001)002<0105: IOSSRV $>2.0 . \mathrm{CO} ; 2$.

Pan, X., X. Li, G. Cheng, H. Li, and X. He, 2015: Development and evaluation of a river-basin-scale high spatio-temporal precipitation data set using the WRF Model: A case study of the Heihe River Basin. Remote Sens., 7, 9230-9252, https:// doi.org/10.3390/rs70709230.

Prasanna, V., J. Subere, D. K. Das, S. Govindarajan, and T. Yasunari, 2014: Development of daily gridded rainfall dataset over the Ganga, Brahmaputra and Meghna river basins. Meteor. Appl., 21, 278-293, https://doi.org/10.1002/met.1327.

Ren, Z., M. Feng, H. Zhang, X. Ju, and Y. Wang, 2007: The difference and relativity between rainfall by automatic recording and manual observation (in Chinese). J. Appl. Meteor. Sci., 3, 358-364.

Rogelis, M. C., and M. G. F. Werner, 2013: Spatial interpolation for real-time rainfall field estimation in areas with complex topography. J. Hydrometeor., 14, 85-104, https://doi.org/10.1175/ JHM-D-11-0150.1.

Sanberg, J. A. M., and J. Oerlemans, 1983: Modeling of Pleistocene European ice sheets: The effect of upslope precipitation. Geol. Mijnbouw, 62, 267-273.

Schiemann, R., D. Lüthi, and C. Schär, 2009: Seasonality and interannual variability of the westerly jet in the Tibetan Plateau region. J. Climate, 22, 2940-2957, https://doi.org/10.1175/ 2008JCLI2625.1.

Shen, Y., and A. Xiong, 2016: Validation and comparison of a new gauge-based precipitation analysis over mainland China. Int. J. Climatol., 36, 252-265, https://doi.org/10.1002/joc.4341.

Shepard, D., 1968: A two-dimensional interpolation function for irregularly-spaced data. ACM 68: Proceedings of the 1968 23rd ACM National Conference, ACM, 517-524, https://doi.org/10.1145/ 800186.810616.

Smith, R. B., and J. P. Evans, 2007: Orographic precipitation and water vapor fractionation over the southern Andes. J. Hydrometeor., 8 , 3-19, https://doi.org/10.1175/JHM555.1.

Sun, Q., C. Miao, Q. Duan, H. Ashouri, S. Sorooshian, and K.-L. Hsu, 2018: A review of global precipitation data sets: Data 
sources, estimation, and intercomparisons. Rev. Geophys., 56, 79-107, https://doi.org/10.1002/2017RG000574.

Tan, M., and Z. Duan, 2017: Assessment of GPM and TRMM precipitation products over Singapore. Remote Sens., 9, 720, https://doi.org/10.3390/rs9070720.

Tang, G., D. Long, Y. Hong, J. Gao, and W. Wan, 2018: Documentation of multifactorial relationships between precipitation and topography of the Tibetan Plateau using spaceborne precipitation radars. Remote Sens. Environ., 208, 82-96, https://doi.org/10.1016/j.rse.2018.02.007.

Taylor, C. M., R. J. Harding, A. J. Thorpe, and P. Bessemoulin, 1997: A mesoscale simulation of land surface heterogeneity from HAPEX-Sahel. J. Hydrol., 188-189, 1040-1066, https:// doi.org/10.1016/S0022-1694(96)03182-4.

Tian, Y., G. J. Huffman, R. F. Adler, L. Tang, M. Sapiano, V. Maggioni, and H. Wu, 2013: Modeling errors in daily precipitation measurements: Additive or multiplicative? Geophys. Res. Lett., 40, 2060-2065, https://doi.org/10.1002/grl.50320.

Tobin, K. J., and M. E. Bennett, 2010: Adjusting satellite precipitation data to facilitate hydrologic modeling. J. Hydrometeor., 11, 966-978, https://doi.org/10.1175/2010JHM1206.1.

Tong, K., F. Su, D. Yang, and Z. Hao, 2014: Evaluation of satellite precipitation retrievals and their potential utilities in hydrologic modeling over the Tibetan Plateau. J. Hydrol., 519, 423-437, https://doi.org/10.1016/j.jhydrol.2014.07.044.

Wang, J., M. Zhang, S. Wang, Z. Ren, Y. Che, F. Qiang, and D. Qu, 2016: Decrease in snowfall/rainfall ratio in the Tibetan Plateau from 1961 to 2013. J. Geogr. Sci., 26, 1277-1288, https:// doi.org/10.1007/s11442-016-1326-8.

Wang, Y., H. Yang, D. Yang, Y. Qin, B. Gao, and Z. Cong, 2017: Spatial interpolation of daily precipitation in a high mountainous watershed based on gauge observations and a regional climate model simulation. J. Hydrometeor., 18, 845-862, https://doi.org/10.1175/JHM-D-16-0089.1.

Webster, P. J., V. O. Magaña, T. N. Palmer, J. Shukla, R. A. Tomas, M. Yanai, and T. Yasunari, 1998: Monsoons: Processes, predictability, and the prospects for prediction. J. Geophys. Res., 103, 14 451-14 510, https://doi.org/10.1029/97JC02719.
Willmott, C. J., C. M. Rowe, and W. D. Philpot, 1985: Small-scale climate maps: A sensitivity analysis of some common assumptions associated with grid-point interpolation and contouring. Amer. Cartogr., 12, 5-16, https://doi.org/10.1559/152304085783914686.

Wood, A. W., L. R. Leung, V. Sridhar, and D. P. Lettenmaier, 2004: Hydrologic implications of dynamical and statistical approaches to downscaling climate model outputs. Climatic Change, 62, 189-216, https://doi.org/10.1023/B:CLIM.0000013685.99609.9e.

Xie, P., M. Chen, S. Yang, A. Yatagai, T. Hayasaka, Y. Fukushima, and C. Liu, 2007: A gauge-based analysis of daily precipitation over East Asia. J. Hydrometeor., 8, 607-626, https://doi.org/ 10.1175/JHM583.1.

Xiong, Z., and X. Yan, 2013: Building a high-resolution regional climate model for the Heihe River Basin and simulating precipitation over this region. Chin. Sci. Bull., 58, 4670-4678, https://doi.org/10.1007/s11434-013-5971-3.

Xu, R, F. Tian, L. Yang, H. Hu, J. Lu, and A. Hou, 2017: Ground validation of GPM IMERG and TRMM 3B42V7 rainfall products over southern Tibetan Plateau based on a high-density rain gauge network. J. Geophys. Res. Atmos., 122, 910-924, https://doi.org/10.1002/2016JD025418.

Yan, D., S. Liu, T. Qin, B. Weng, C. Li, Y. Lu, and J. Liu, 2017: Evaluation of TRMM precipitation and its application to distributed hydrological model in Naqu River Basin of the Tibetan Plateau. Hydrol. Res., 48, 822-839, https://doi.org/ 10.2166/nh.2016.090.

Ye, B., D. Yang, Y. Ding, and T. Han, 2007: A bias-corrected precipitation climatology for China. Acta Geogr. Sin., 62, 3-13, https://doi.org/10.11821/xb200701001.

Young, C. B., B. R. Nelson, A. A. Bradley, J. A. Smith, C. D. Peters-Lidard, A. Kruger, and M. L. Baeck, 1999: An evaluation of NEXRAD precipitation estimates in complex terrain. J. Geophys. Res., 104, 19691-19703, https://doi.org/ 10.1029/1999JD900123.

Zhang, K., J. S. Kimball, R. R. Nemani, and S. W. Running, 2010: A continuous satellite-derived global record of land surface evapotranspiration from 1983 to 2006. Water Resour. Res., 46, W09522, https://doi.org/10.1029/2009WR008800. 